\title{
Long-Lead Predictions of Warm Season Droughts in South Korea Using North Atlantic SST
}

\author{
BOKSOON MYOUNG AND JINYOUNG RHEE \\ APEC Climate Center, Busan, South Korea \\ CHANGHYUN YOO \\ Department of Climate and Energy Systems Engineering, Ewha Womans University, Seoul, South Korea
}

(Manuscript received 29 January 2019, in final form 10 January 2020)

\begin{abstract}
Understanding and predicting warm season (May-October) droughts is critically important in South Korea for agricultural productivity and water resource management. Using a 6-month standardized precipitation index ending in October (SPI6_Oct), we investigate the interannual variability of warm season droughts and the related large-scale atmospheric circulations for the most recent 20-yr period (1995-2014). Cyclonic (anticyclonic) circulations to the east of Japan (in the North Pacific) tend to induce warm season droughts (wetness) by suppressing (enhancing) moist water transport from the south of the Korean Peninsula. These circulation patterns to the east of Japan are linked to a barotropic Rossby wave-like teleconnection pattern from the North Atlantic to East Asia, which is found to be responsible for the interannual variability of SPI6_Oct. This teleconnection pattern is highly correlated with the difference in sea surface temperature (SST) between the Norwegian Sea and the Barents Sea (referred to as NA_dipole) in January-March $(r=0.68)$, which modulates the snow depth over the Ural Mountains in spring and the sea ice concentration over the Barents Sea during the entire warm season. Two drought prediction models, an empirical model and a hybrid machine learning model, are developed and tested for their predictive skills for South Korea. An empirical prediction model using NA_dipole as one of the predictors is found to accurately capture the interannual variability of SPI6_Oct $\left(r^{2}=53 \%\right)$. NA_dipole is found to improve the predictive skills of the hybrid machine learning drought prediction model, especially for longer lead times. Our results emphasize the significant role of North Atlantic SST anomalies in warm season medium-range droughts in South Korea.
\end{abstract}

\section{Introduction}

South Korea has a humid continental climate according to Köppen's climate classification, and it receives most of its annual precipitation total $(\sim 79 \%)$ during its warm season of May-October (i.e., the period during which the monthly mean temperature is greater than $14^{\circ} \mathrm{C}$ ). The warm season precipitation includes the intense and prolonged East Asian monsoon rainfall, locally known as changma, from mid-June to late July. Droughts in spring in general do not last long because they can be halted by the changma. In contrast, droughts in summer can last until the subsequent spring (Kim et al. 2009). Warm season droughts refer to the droughts that span across these two seasons. If a warm season drought in

Corresponding author: Boksoon Myoung,bmyoung@apcc21.org the previous year continues into the subsequent spring, it may cause serious shortages of agricultural water resources, agricultural droughts, and failure in planting. As such, the prediction of warm season droughts is important for agricultural water resource management and disaster preparation in South Korea.

Although the annual precipitation total in South Korea shows an increasing trend (Jung et al. 2011), precipitation variability has also increased, and longterm droughts lasting longer than one year occasionally take place, such as in 1994-95 and 2013-16 (Kwon et al. 2016). In addition, the risk of drought in the Korean Peninsula is expected to increase due to continued global warming (Boo et al. 2006; Yoo et al. 2012). Nevertheless, previous studies on the causes of meteorological droughts in South Korea are sparse compared to those on changma-related precipitation variability (Lee and Seo 2013; Park et al. 2015; Jeong et al. 2017). 
Most previous drought studies have focused on shortterm droughts, such as those during the month of May or individual seasons (i.e., spring or summer). Several studies have reported lagged linkages between atmospheric teleconnection patterns [e.g., the North Atlantic Oscillation (NAO)] and the precipitation variability and droughts of South Korea in spring or summer (Sung et al. 2006; Z. Wu et al. 2009; Seo et al. 2012; Lee and Seo 2013). The mechanisms responsible for this connection include the barotropic atmospheric teleconnection from the North Atlantic to East Asia and modulation by snow depth in Eurasia (Kripalani et al. 2002; Wu and Kirtman 2007).

Impacts of El Niño-Southern Oscillation (ENSO) on precipitation variability and droughts in South Korea have also been extensively investigated (Kang 1998; Cha et al. 1999; Kug et al. 2010; Ho et al. 2016; Lee et al. 2019); however, the results are not consistent. One study asserts that there is increased summer precipitation in $\mathrm{El}$ Niño years (Kang 1998), and others have suggested lower summer precipitation and the delayed onset of the changma in El Niño summers (Ahn et al. 1997; Cha et al. 1999). Recent studies at finer time scales have found that, during El Niño developing periods, precipitation decreases in September and increases in December (Son et al. 2014, 2016; Yeo et al. 2018). The inconsistent connection between ENSO and precipitation in South Korea can be attributed to the various impacts of the different types of El Niño (Ashok et al. 2007; Kao and Yu 2009; Kug et al. 2009; Yeh et al. 2009, 2015), the different impacts of ENSO events in developing/decaying periods, the asymmetric impacts of El Niño and La Niña to the atmosphere (Capotondi et al. 2015), and/or differences between research periods.

Regarding these various factors, it should be noted that the characteristics of summer precipitation and monsoons in East Asia, including the changma, have changed since the climate shift in the mid-1990s (Kwon et al. 2005; Xiang and Wang 2013; Chen and Zhou 2014; Choi et al. 2017). The timing of the climate shift coincides with the anomalous sea surface temperature (SST) tendencies observed in the central Pacific (e.g., central Pacific-type El Niño) and with Atlantic warming (i.e., the negative to positive phase transition of the Atlantic multidecadal oscillation; Yu and Paek 2015; Wang et al. 2017; Vecchi et al. 2017). Therefore, consideration of the climate shift in the mid-1990s may be important in identifying key factors related to precipitation variability and droughts.

As described above, because warm season droughts are likely to develop into long-term droughts and severe spring droughts in South Korea, an examination of the characteristics and mechanisms of warm season droughts and their prediction is critical. Statistical predictive models are commonly used for this purpose, and a few studies have attempted to predict seasonal or monthly hydrological droughts in South Korea with 1-3month lead times (e.g., Shin et al. 2016; Bae et al. 2017). Dynamical approaches have also been employed, with Sohn et al. (2013) applying the Asia-Pacific Economic Cooperation (APEC) Climate Center's (APCC) multimodel ensemble (MME) seasonal forecast outputs to spring drought prediction in South Korea. Based on this, they developed a hybrid dynamical-statistical predictive model for winter-to-spring drought in South Korea and produced a better performance compared to a model employing APCC MME seasonal prediction alone (Sohn and Tam 2016). Diverse machine learning models have also been applied to drought studies (e.g., Park et al. 2018; Tadesse et al. 2017; Lee et al. 2019; Rhee and Yang 2018). A recent study on meteorological drought forecasting in ungauged areas of South Korea (Rhee and Im 2017) applied three machine learning models-decision trees, random forest, and extremely randomized trees models (extratrees; Geurts et al. 2006) - and found that the extratrees model performed the best in most cases.

The present study aims to investigate the large-scale circulations that cause meteorological droughts during the warm season (e.g., Stephan et al. 2018; Preethi et al. 2019) and to develop long-lead drought prediction models (both empirical and hybrid machine learning). Potential predictors identified in this study include the SST in the Pacific, North Atlantic, and Indian Oceans. Employing primary predictors, two drought prediction models are developed and tested: an empirical linear regressive model and a hybrid model in which the primary predictors are embedded in a machine learning model. For the hybrid model, the extratrees model is used due to its superiority in drought forecasting (Rhee and Im 2017) and APCC MME model forecasts are also employed. As a result, this hybrid model, which combines statistical, dynamical, and machine learning approaches, is found to have substantially higher predictive power for warm season droughts in South Korea, especially with long lead times. In these investigation and model development processes, we focus on the two decades after the mid-1990s climate shift and examine decadal changes of the relationships of SSTs with drought index.

\section{Data and methods}

\section{a. Drought index}

The daily precipitation records of 94 Automated Synoptic Observing System stations are obtained from the Korea Meteorological Administration (KMA) and 


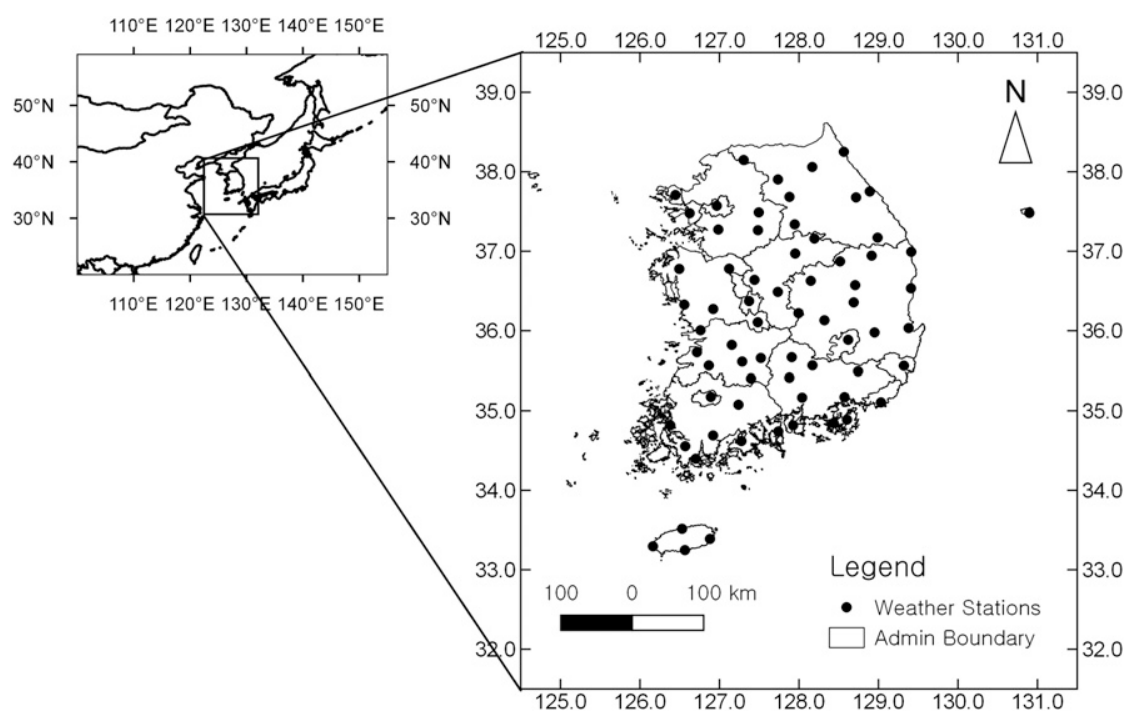

FIG. 1. Locations of 68 weather stations used in the study in South Korea.

converted into monthly data. The amount of precipitation is measured either by heated tipping-bucket (both 0.1 - and $0.5-\mathrm{mm}$ resolution) or auto-emptying weightmeasuring (0.1-mm resolution) rain gauges. The accuracy of weight-measuring rain gauges is known to be $\pm 0.1 \mathrm{~mm}$ (for precipitation $<10 \mathrm{~mm}$ ) or $\pm 1 \%$ (for precipitation $\geq$ $10 \mathrm{~mm}$ ), and the uncertainty is less than $0.005 \mathrm{~mm}$ (Hong et al. 2018). A tipping-bucket rain gauge with a $0.1-\mathrm{mm}$ resolution effectively measures precipitation levels when the amount of rainfall is low and the precipitation intensity is weak, while one with a $0.5-\mathrm{mm}$ resolution produces smaller errors when the precipitation intensity is strong (Park et al. 2009).

Of the 94 stations, 68 are employed in the present study because they have less than $20 \%$ missing monthly data for the long-term calibration period of 1983-2017 (Fig. 1). The standardized precipitation index (SPI; Edwards and McKee 1997) is constructed by accumulating the precipitation data for a desired time scale, fitting the precipitation distribution to a gamma distribution, and finally converting it into a normal standard distribution with zero mean and unit variance. For example, the 6-month SPI for October is derived using the precipitation from May to October. The SPI index obtained from individual stations (SPI6) is used for the development of the hybrid machine learning model. The SPI index obtained from the average precipitation across the 68 selected stations (SPI6_Oct) is used for meteorological analyses, the identification of potential predictors, and the development of the empirical regressive model.

\section{b. Meteorological analyses}

We use $2.5^{\circ} \times 2.5^{\circ}$ resolution data for geopotential height at the 500- and 850-hPa levels (HGT_500 and HGT_850, respectively), horizontal winds at the same levels, and vertical velocity (omega) at $500 \mathrm{hPa}$ (OMG_500), from the National Centers for Environmental Prediction-National Center for Atmospheric Research Reanalysis (R1; Kalnay et al. 1996). The SST and the outgoing longwave radiation (OLR) at the top of the atmosphere are obtained from the SST extended version $4\left(2^{\circ} \times 2^{\circ}\right)$ and monthly interpolated OLR $\left(2.5^{\circ} \times 2.5^{\circ}\right)$ datasets from the National Oceanic and Atmospheric Administration (NOAA), respectively. We also used $0.5^{\circ} \times 0.5^{\circ}$ precipitation data from the Climate Research Unit (CRU). Monthly values for the Niño-3.4, Southern Oscillation index (SOI; Ropelewski and Jones 1987), Pacific decadal oscillation (PDO; Zhang et al. 1997; Mantua et al. 1997), and multivariate ENSO index (MEI) are taken from the NOAA Climate Prediction Center archives (http://www.esrl.noaa.gov/psd/data/ climateindices/list/). For snow depth, we use the ERAInterim dataset from the European Centre for MediumRange Weather Forecasts (Dee et al. 2011). Last, the sea ice concentration from the National Snow and Ice Data Center (Comiso 2017) is analyzed. These meteorological datasets have been widely used in South Korea for various climate studies (Jeong et al. 2013; Ahn et al. 2014; Lee and Hong 2014; Lee and Lee 2016; Yeh et al. 2018).

The primary analysis period is from 1995 to 2014, which considers the potential impacts of the climate shift in the mid-1990s on regional weather conditions in South Korea (Kwon et al. 2005; Xiang and Wang 2013; Chen and Zhou 2014; Choi et al. 2017). The years 1975-94 are also analyzed and used for comparison with the primary period. Three years 
TABLE 1. Dry and wet composite years for the research period (1995-2014). Years with SPI6_Oct less than -0.5 are defined as dry years and those greater than 0.5 are defined as wet years.

\begin{tabular}{cc}
\hline \hline Dry years & Wet years \\
\hline $1996,2001,2008,2013,2014$ & $1998,1999,2003,2007,2011$ \\
\hline
\end{tabular}

from 2015 to 2017 are used to test the prediction models.

For the relationships between the variables, we compute the linear correlation coefficients between the variables both before and after removing the linear long-term trends for each variable. The results in section 3 are from the analyses performed on the detrended data except when constructing the empirical linear regression model for drought prediction; the original data including the linear trends yield essentially the same results (except for the high-latitude North Atlantic and Arctic regions). The resulting Pearson correlation coefficients (CCs) indicate the strength of the linear relationship between two fields. Assuming independent and normally distributed data, $0.44(0.33)$ is the $95 \%$ confidence level for a nonzero correlation for the 20-yr (40-yr) samples with 18 (38) degrees of freedom (i.e., $N-2 ; N$ is the total number of samples).

Composite analysis of the dry and wet years presented in Table 1 is conducted for the oceanic and atmospheric variables. For the composite analysis, after removing the linear trend from the SPI6_Oct data, we select the dry (wet) years from SPI6_Oct as those less (greater) than -0.5 (0.5) (Table 1). These threshold values represent an optimization compromise between a small sample and signal-to-noise ratio. Statistical significance tests for the composite analysis are also performed using the bootstrap resampling technique by repeating 1000-time random selections without replacement.

For potential predictors, SST variables are often chosen because they are considered to be a slowly varying boundary condition (Lau et al. 2000; Yim et al. 2015; Lee and Seo 2013). In the present study, potential predictors for the 6-month lead time are selected based on the strong relationship between SPI6_Oct and JanuaryMarch (JFM) averaged SST.

\section{c. Hybrid machine learning drought modeling}

Extratrees machine learning models are built for 1-6-month lead drought predictions (Fig. 2). Extratrees models are based on decision trees (Quinlan 1986), which are the basis of many rule-based machine learning models. This is a supervised learning method that performs either classification or regression based on a tree with leaf nodes and branches. Input data are split at each node optimizing a split function. The maximum depth of the tree, which is the number of tree nodes (other than the root) along the longest path from the tree root to a leaf, can be determined by the user. Extratrees models use an ensemble of trees to avoid overfitting, which is often a problem for a single tree. Instead of using a split function, random splits are made at each node, and the one with the best results is selected. The number of trees can also be determined by the user, and all trees participate in deciding the final results.

The observed SPI6 for the current month (SPI6_P) at individual weather stations is included as an input variable for considering the initial drought conditions. The forecasted SPI6 for the target month based on biascorrected seasonal forecasts (SPI6_F) is included to utilize the forecasting skill of the APCC MME model. Potential predictors identified in section $3 \mathrm{~b}$ are included, as well as ancillary data of latitude (LAT), longitude

\section{Input Variables}

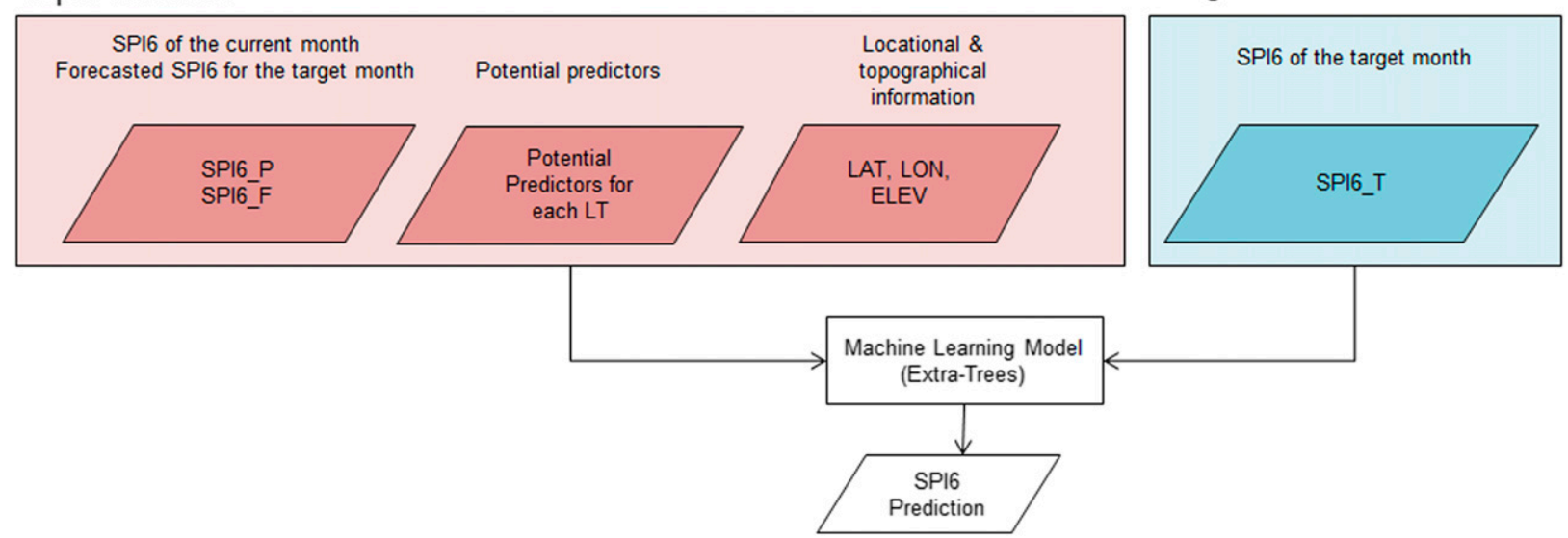

FIG. 2. Flow diagram of the hybrid machine learning models. 


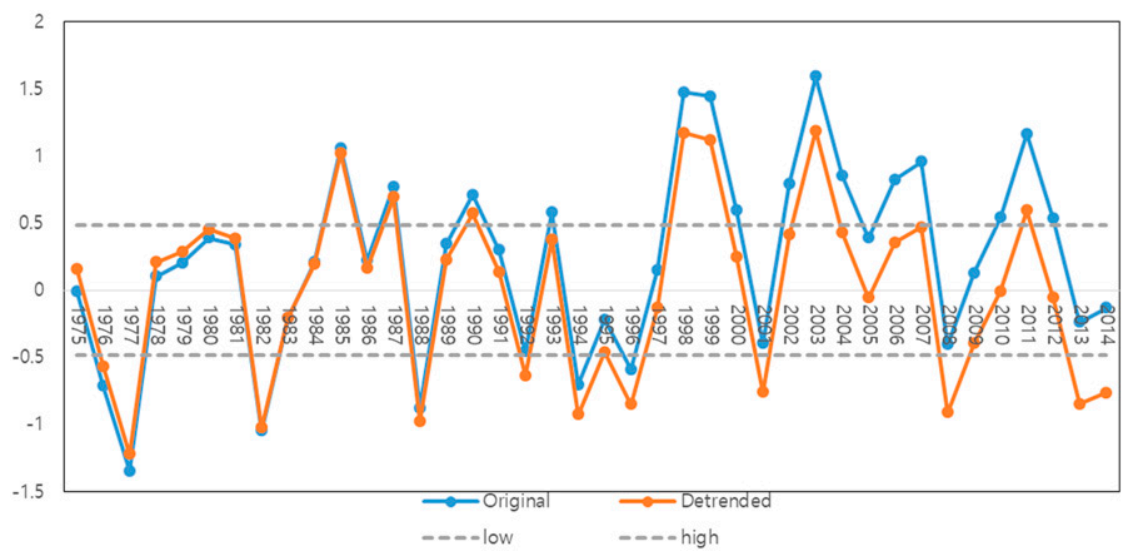

FIG. 3. The 40-yr (1975-2014) time series of original (blue) and detrended (orange) SPI6 in October (SPI6_Oct). Years with SPI6_Oct less than -0.5 (dashed gray with "low") are defined as dry years while those with SPI6_Oct greater than 0.5 (dashed gray with "high") are defined as wet years.

(LON), and elevation (ELEV) of individual weather stations. In the present study, the target variable is the observed SPI6 of the target month (SPI6_T) at individual weather stations. For example, the input vector for the 6-month-lead model from a weather station in 1995 has values of the observed SPI6 in April (SPI6_P), the MME forecasts for October in May (SPI6_F), potential predictors in JFM, latitude, longitude, and elevation of the station (LAT, LON, and ELEV, respectively). The target variable is the observed SPI6 in October (SPI6_T) in 1995.

The idea of combining seasonal forecasts and including potential predictors in the data-driven models is adopted from previous studies (Rhee and Im 2017; Rhee and Yang 2018). Since we focus on the contribution of potential predictors in drought forecasting, we exclude the use of remote sensing variables, which have been required in previous studies for predictions for ungauged areas (Fig. 2).

Data from 1995-2014 are used for the tuning of model parameters, with 10-fold cross-validation used to determine the number of trees (among 10, 50,100,200, and $500)$ and the maximum depth of tree growth $(3,5,10,15$, and the full growth). The models are then trained using data from 1995 to 2014 with selected model parameters and tested using data from 2015 to 2017 for the final evaluation.

\section{Results and discussion}

\section{a. Large-scale circulations associated with the warm season drought}

Figure 3 shows the 40-yr (1975-2014) time series for the original (blue) and detrended (orange) drought index data (SPI6_Oct). The recent multiyear drought event in 2013-14 is illustrated clearly by the detrended index.

To understand the large-scale circulations associated with the variability of SPI6_Oct, interannual correlations of SPI6_Oct are computed with SST, OLR, and HGT_500 that are averaged for the MayOctober period (Figs. 4a-c, respectively). Composite maps of HGT_500,HGT_850 with wind vectors, SST, and OLR averaged for the May-October period in the dry and wet composite years are also presented in Figs. 5 and 6, respectively.

For SST (Fig. 4a), positive correlations are observed from east of Japan to the date line (near $\left.30^{\circ} \mathrm{N}\right)$. In the same region, positive correlations are also found with OLR (Fig. 4b) and with HGT_500 (Fig. 4c). These correlations indicate that precipitation in South Korea decreases when that east of Japan increases with cyclonic circulations. The results of the composite analysis are also consistent; in the dry years (Figs. 5a,b), cyclonic circulations are dominant in east of Japan while weak anticyclonic circulations are found on the Korean Peninsula. As a result, northeasterly wind anomalies prevail to the southeast, reducing precipitation in South Korea by impeding the movement of warm and moist air incoming from the south. Cold SSTs east of Japan are due to the reduced solar insolation (data not shown) associated with the enhanced precipitation in the region. The opposite is true for the wet years, as displayed in Fig. 6.

In addition, SST and OLR in the tropical Pacific are not significantly correlated with SPI6_Oct (Figs. 4a,b), indicating negligible linear relationships with ENSO. As discussed in the introduction, previous studies on the 
May-Oct (simul.)
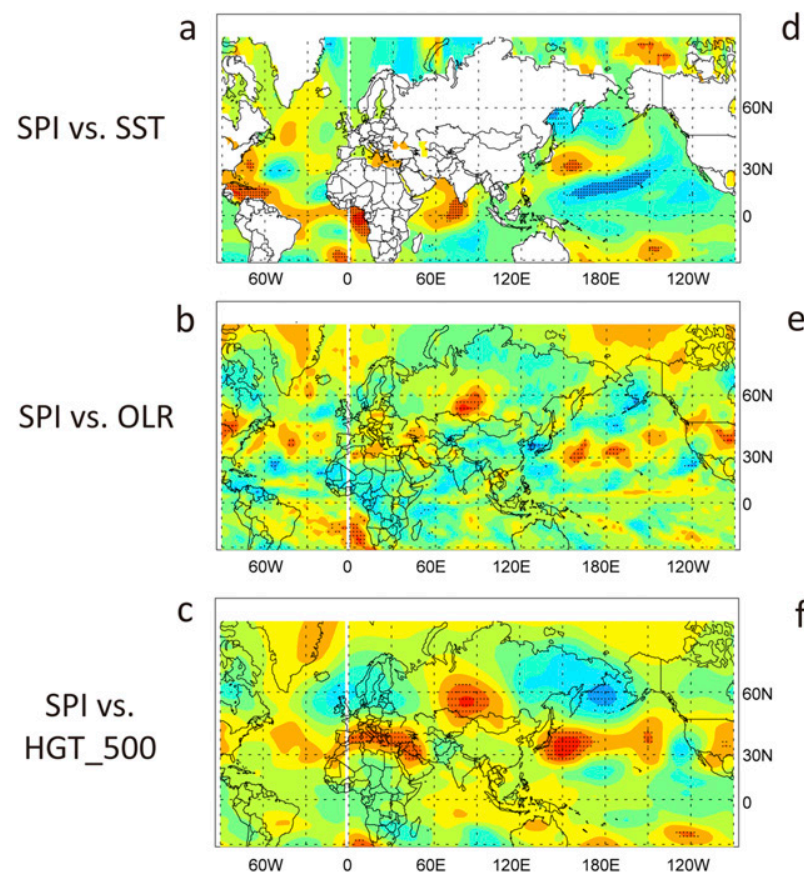

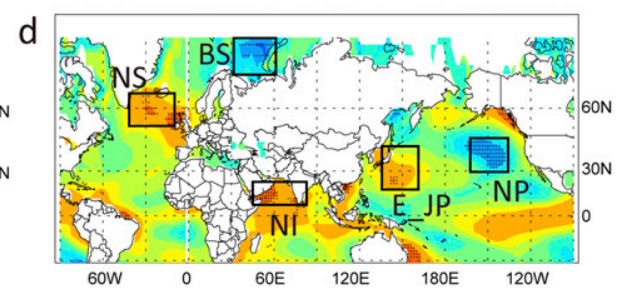

e

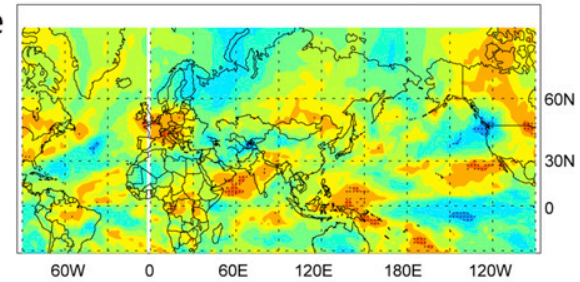

f

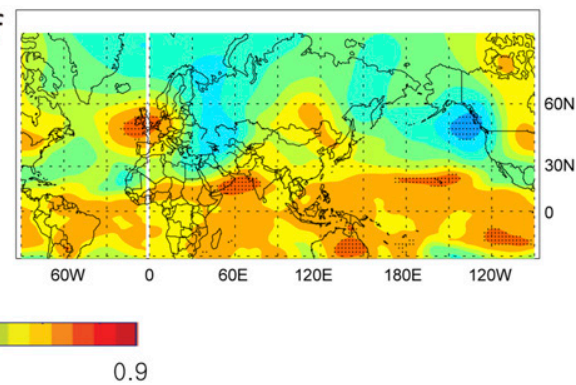

FIG. 4. Correlation map of SPI6_Oct with May-October averaged (a) SST, (b) OLR, and (c) HGT at $500 \mathrm{hPa}$ for the 20 years (1995-2014). (d)-(f) As in (a)-(c), but with January-March averaged SST, OLR, and HGT at $500 \mathrm{hPa}$, respectively. Correlations being statistically significant at the $95 \%$ confidence level are indicated by dots. Potential predictors are shown in the black boxes in (d).

impacts of ENSO on precipitation in South Korea have reported conflicting results (Kang 1998; Cha et al. 1999; Kug et al. 2010; Ho et al. 2016). To test the nonlinear relationships with ENSO (possibly due to different impacts of ENSO events during developing/decaying periods, the asymmetric impacts of El Niño and La Niña to the atmosphere, and/or differences between research periods), we compare the dry-year composites of SST anomalies and monthly ENSO indices to the wet-year composites. The results show that negative SST anomalies in the central tropical Pacific are weak in the dry years (Fig. 5c) but are robustly strong in the wet years, resembling La Niña patterns (Fig. 6c). The wetter tendency in $\mathrm{La}$ Niña years is true because the time series for the SOI in the wet years is positively skewed after August, and the positive values are greater than 1.5 in December (Fig. 7b). In the dry years, however, the SOI exhibits a mix of positive and negative values after August (Fig. 7a). Similar results with the opposite signs are found with the other ENSO indices such as the Niño3.4, MEI, and PDO (not shown). This indicates a nonlinear response of the warm season drought index in South Korea to ENSO; extremely wet warm seasons tend to occur in La Niña-developing summers, whereas warm season droughts are less sensitive to ENSO.

For HGT_500, strong and significant linear correlations are found in the midlatitudes (Fig. 4c). In particular, over the Eurasian continent, significant positive correlations are found in southern Europe, east of the Ural Mountains, and east of Japan, while negative correlations are found in northern Europe and in the Sea of Okhotsk, which resembles waveblocking or Rossby wave-like teleconnection patterns from the North Atlantic to East Asia. This feature of the geopotential height field is also observed in the composite analysis (Figs. 5a and 6a) and is more obvious in the dry years than in the wet years. Many previous studies have pointed out that atmospheric and oceanic variability in the North Atlantic, including the NAO, affects East Asian monsoons at time scales from a few weeks to several months (Sung et al. 2006; Z. Wu et al. 2009; Seo et al. 2012; Lee and 
a) HGT_500

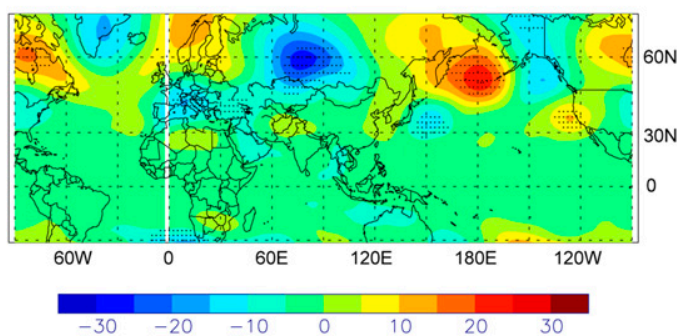

c) SST

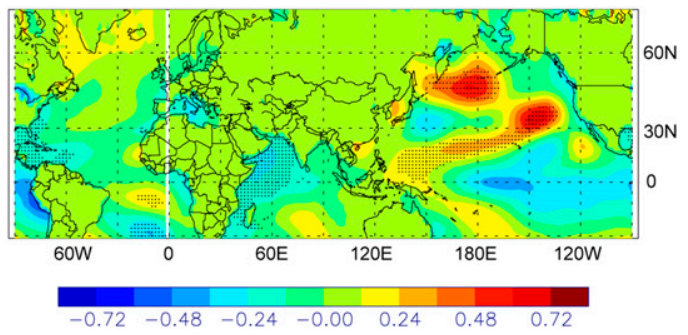

b) HGT_850 with Winds

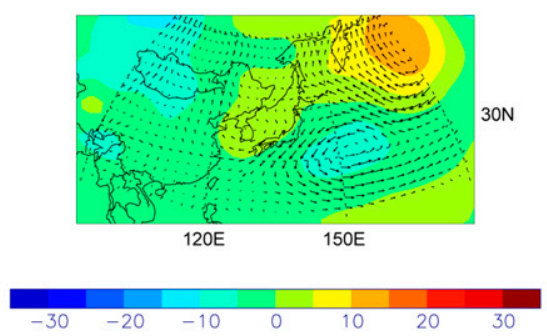

d) OLR

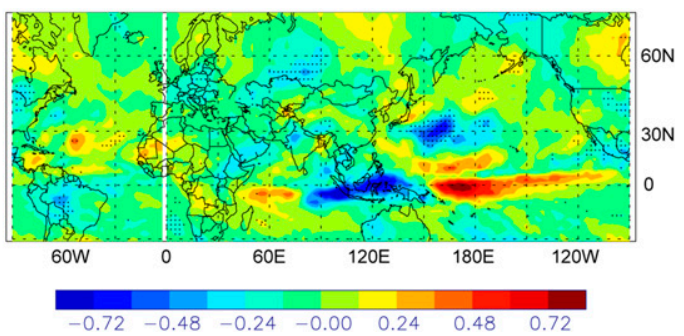

FIG. 5. The 6-month (May-October) averaged (a) HGT at $500 \mathrm{hPa}(\mathrm{m}$ ), (b) $\mathrm{HGT}$ at $850 \mathrm{hPa}$ (m) with winds $\left(\mathrm{m} \mathrm{s}^{-1}\right)$, (c) SST $\left({ }^{\circ} \mathrm{C}\right)$, and $(\mathrm{d})$ OLR $\left(\mathrm{W} \mathrm{m}^{-2} \times 10\right)$ in the dry years. Regions statistically significant at the $95 \%$ confidence level are indicated by dots.

Seo 2013). In line with these studies, the results in the present study suggest that a Rossby wave-like teleconnection pattern in the atmosphere is linearly associated with precipitation variability in South Korea during the warm season and consequently SPI6_Oct. This pattern has an equivalent barotropic structure, as seen in the upper- and lower-troposphere (data not shown). a) HGT_500

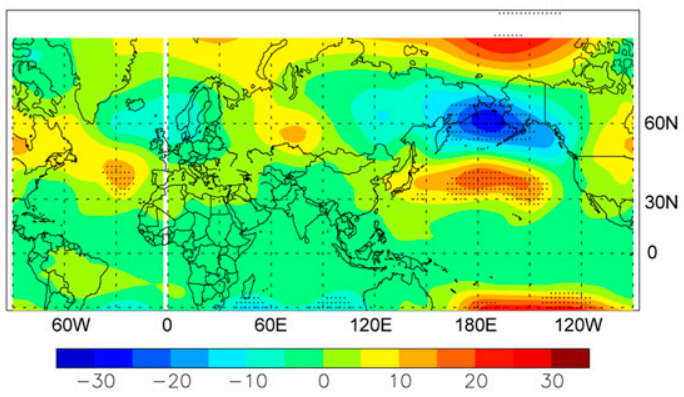

c) SST

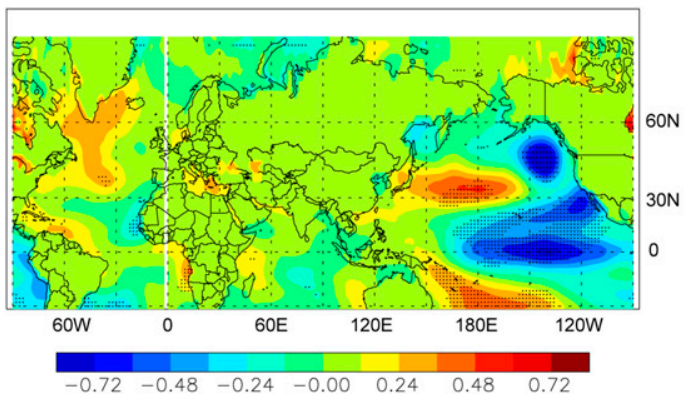

b) HGT_850 with Winds

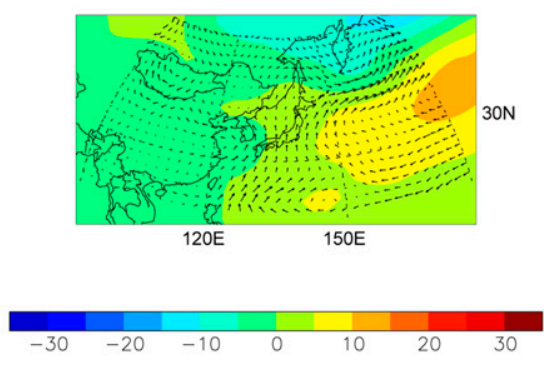

d) OLR

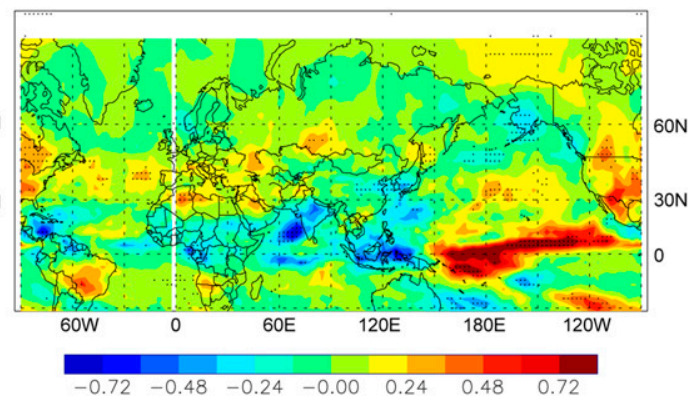

FIG. 6. As in Fig. 5, but in wet years. 

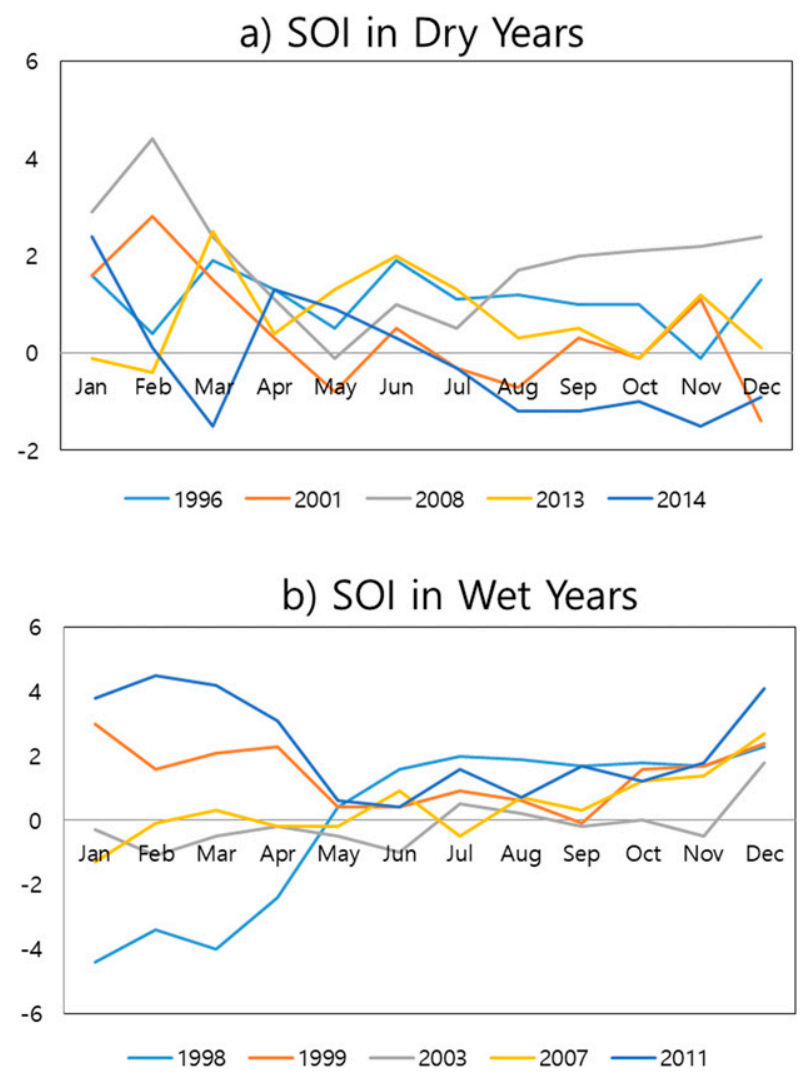

FIG. 7. Time series of the Southern Oscillation index (SOI) in (a) the dry years and (b) the wet years.

\section{b. Potential predictors}

To identify potential predictors for a 6-month lead time from April to October, correlations between SPI6_Oct and detrended SSTs averaged from January to March (JFM) are shown in Fig. 4d, allowing April for data acquisition. In the same way, correlations between SPI6_Oct and both OLR and HGT are presented in Figs. $4 \mathrm{e}$ and $4 \mathrm{f}$, respectively.

For SSTs (Fig. 4d), significant correlations are observed in the North Pacific, North Indian, North Atlantic, and the Barents Sea. These correlation patterns tend to be maintained in the warm season (Fig. 4a). Of these, we select the SST averages for east of Japan (E_JP), northeastern Pacific (NP), the Norwegian Sea (NS), the Barents Sea (BS), and the north Indian Ocean (NI) as potential predictors, indicated by the rectangular boxes. Their correlation coefficients (both original and detrended) with SPI6_Oct are listed in Table 2.

For the E_JP, positive correlations with SST, OLR, and HGT_500 are observed in JFM (Figs. 4d-f) as well as in the warm season (Figs. $4 \mathrm{a}-\mathrm{c}$ ), although some of these are not statistically significant (Figs. 4e,f).
This indicates that the same conditions (i.e., wet and cold conditions with cyclonic circulations) seem to be maintained from the previous cold season to the current warm season, inhibiting the influx of warm moist air from the south and reducing precipitation and SPI6_Oct in South Korea.

For the SST in the North Atlantic, a warmer NS in spring has been known to affect East Asian monsoons and increase summer precipitation in Korea (Sung et al. 2006; Z. Wu et al. 2009; Seo et al. 2012; Lee and Seo 2013). In particular, Lee and Seo (2013) found that NS in spring is one of the key predictors of changma precipitation by inducing teleconnection in Eurasia and anticyclonic circulations in east of Japan. The teleconnection pattern reported in their study is similar to the wavelike pattern observed in the correlation between SPI6_Oct and HGT_500 in Fig. 4c (i.e., positive in the midlatitude Atlantic, negative in western Europe, positive east of the Ural Mountains, and positive east of Japan). We found that both NS and BS are significantly correlated with SPI6_Oct ( $r=0.51$ and -0.59 in Table 2, respectively). Because NS and BS are significantly negatively correlated with each other $(r=-0.48)$, we refer hereafter to the difference in the SST between NS and BS as NA_dipole. A higher correlation is found between SPI6_Oct and the NA_dipole in JFM $(r=0.66)$ than between SPI6_Oct and NS or BS individually.

To examine how the NA_dipole affects SPI6_Oct, the correlations between the NA_dipole and HGT_500 averaged for May-July (MJJ), August-October (ASO), and May-October are displayed in Figs. 8a-c. The correlations between the NA_dipole and vertical velocity and between the NA_dipole and precipitation are also shown in Figs. 8d-f and Figs. 8g-i, respectively. The spatial patterns of the correlations in Fig. 8c are very similar to those in Fig. 4c, especially in the Northern Hemisphere; they are negative in northern Europe, positive in southern Europe and east of the Ural Mountains, positive east of Japan, and negative in the Sea of Okhotsk and the Bering Sea. These results suggest that the NA_dipole in the late winter and early spring significantly influences warm season precipitation and subsequently the drought index in South Korea with a 6-month temporal lag. This long temporal lag between the NA_dipole and SPI6_Oct is very interesting. The NA_dipole may affect warm season precipitation by influencing landocean boundary conditions such as snow depth and cover in Eurasia (Kripalani et al. 2002; Wu and Kirtman 2007), sea ice in polar regions (Guo et al. 2014; Li et al. 2018), and/or long ocean memory, including the reemergence of the wintertime SST tripole in the North Atlantic 7-9 months later (Watanabe and Kimoto 2000a,b; Gastineau and Frankignoul 2015). 
TABLE 2. List of potential predictors and the lagged 20-yr correlations with SPI6_Oct. Detrended correlations are shown with the original correlations in parentheses. Bold text indicates statistical significance at the $95 \%$ confidence level.

\begin{tabular}{lcccc}
\hline \hline & & \multicolumn{2}{c}{ Detrended 20-yr correlation (original) } \\
\cline { 3 - 5 } \multicolumn{1}{c}{ Name } & Region in Fig. 4d & OND & JFM & AMJ \\
\hline East of Japan (E_JP) & $138^{\circ}-162^{\circ} \mathrm{E}, 22^{\circ}-46^{\circ} \mathrm{N}$ & $0.03(0.01)$ & $0.36(0.34)$ & $0.38(0.36)$ \\
Norway Sea (NS) & $44^{\circ}-20^{\circ} \mathrm{W}, 56^{\circ}-64^{\circ} \mathrm{N}$ & $\mathbf{0 . 6 2}(0.56)$ & $\mathbf{0 . 5 1}(\mathbf{0 . 4 5})$ & $0.14(0.12)$ \\
Barents Sea (BS) & $30^{\circ}-60^{\circ} \mathrm{E}, 70^{\circ}-80^{\circ} \mathrm{N}$ & $\mathbf{- 0 . 4 9}(-0.27)$ & $\mathbf{- 0 . 5 9}(-0.39)$ & $\mathbf{- 0 . 5 2}(-0.34)$ \\
NA_dipole & $\mathrm{NS}$ minus BS & $\mathbf{0 . 7 0}(\mathbf{0 . 6 8})$ & $\mathbf{0 . 6 6}(\mathbf{0 . 6 8})$ & $0.36(0.36)$ \\
Northeastern Pacific (NP) & $168^{\circ}-136^{\circ} \mathrm{W}, 30^{\circ}-48^{\circ} \mathrm{N}$ & $\mathbf{- 0 . 5 7}(\mathbf{- 0 . 5 4})$ & $\mathbf{- 0 . 4 8}(-0.40)$ & $-0.30(-0.20)$ \\
North Indian Ocean (NI) & $46^{\circ}-80^{\circ} \mathrm{E}, 10^{\circ}-22^{\circ} \mathrm{N}$ & $\mathbf{0 . 6 8}(\mathbf{0 . 6 7})$ & $\mathbf{0 . 4 8}(\mathbf{0 . 4 7})$ & $-0.02(-0.04)$ \\
\hline
\end{tabular}

We find that the NA_dipole affects SPI6_Oct by modulating not only the springtime snow depth in Eurasia (Figs. 9a,b) but also the spring-to-early summer sea ice in the Barents Sea (Figs. 9c-f). The snow depth and sea ice could maintain the NA_dipole forcing for as long as a season. In fact, Guo et al. (2014) and Li et al. (2018) reported that scarce springtime sea ice concentration in the Barents Sea is likely to cause severe summer droughts in northeastern China and Arctic sea ice in spring strongly affects the East Asian monsoon

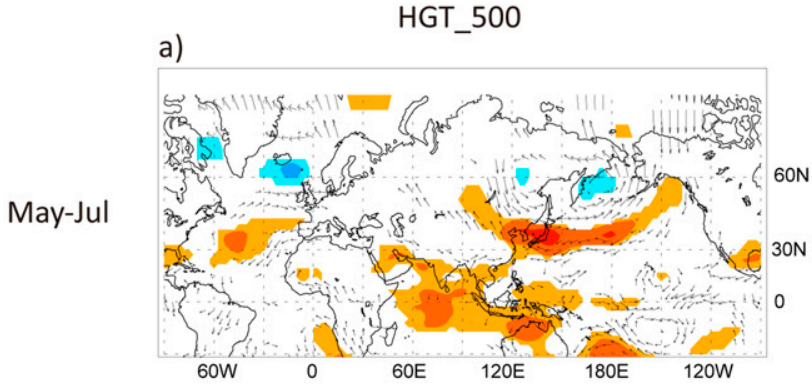

b)

Aug-Oct

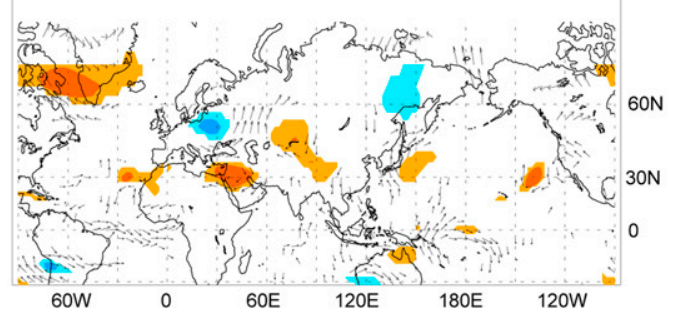

c)

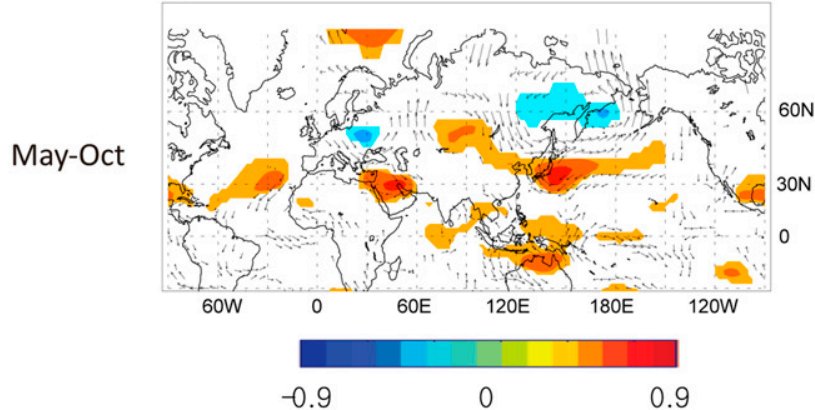

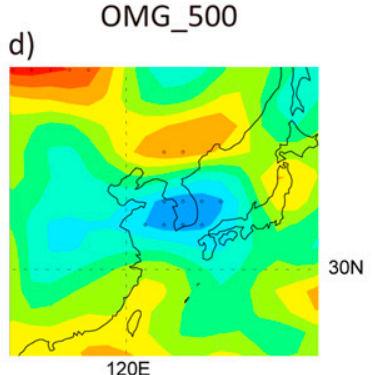

e)

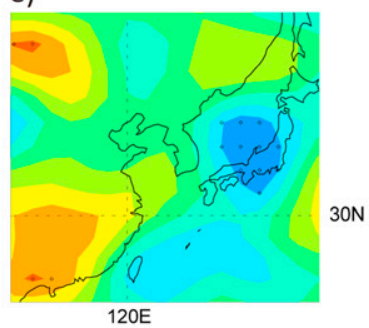

f)

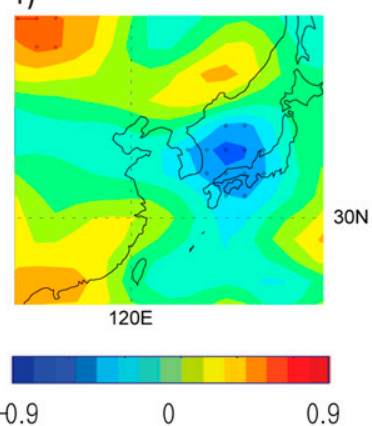

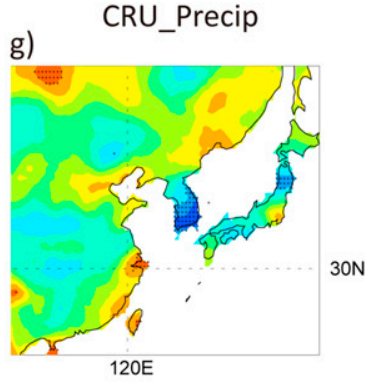

h)

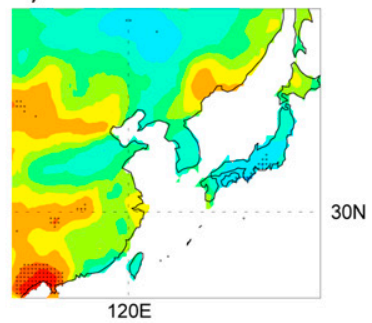

i)

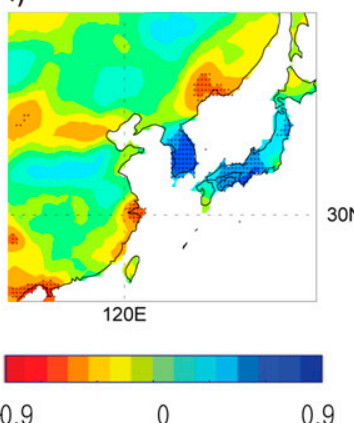

FIG. 8. Correlation coefficients of the NA_dipole index with HGT and wind at $500 \mathrm{hPa}$ averaged over (a) the first three months, May-July, (b) the latter three months, August-October, and (c) the whole warm season, May-October. Only correlations that are statistically significant at the 95\% confidence level are shown. (d)-(f) As in (a)-(c), but with the vertical velocity at 500 hPa (OMG_500). (g)-(i) As in (a)-(c), but with the CRU precipitation. In (d)-(i), regions statistically significant at the $95 \%$ confidence level are indicated by dots. 


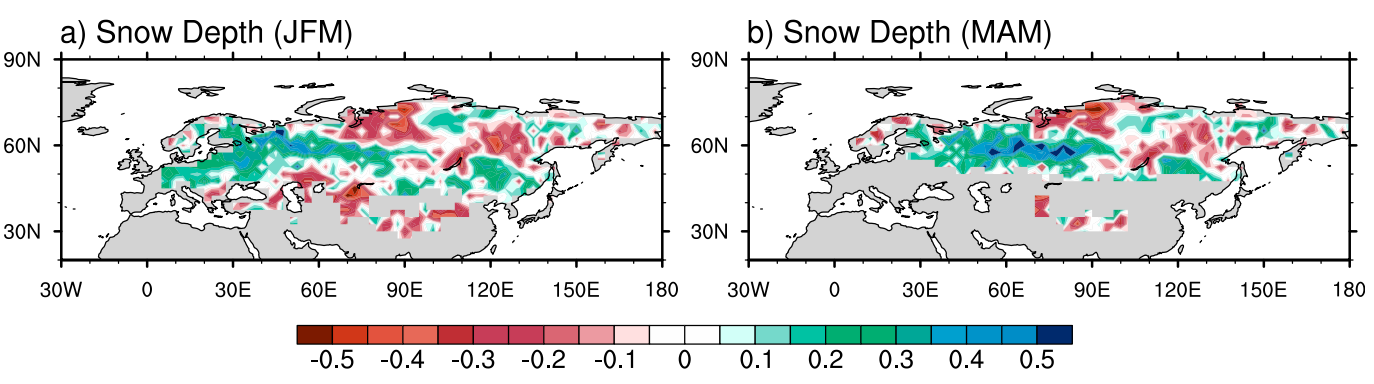

c) SIC (JFM)

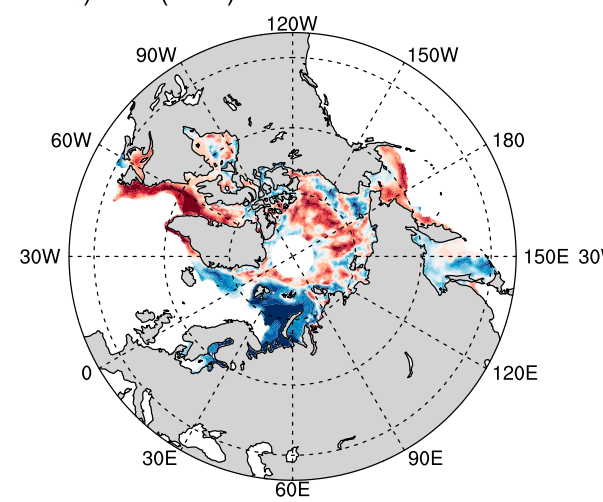

d) SIC (MAM)

e) SIC (MJJ)
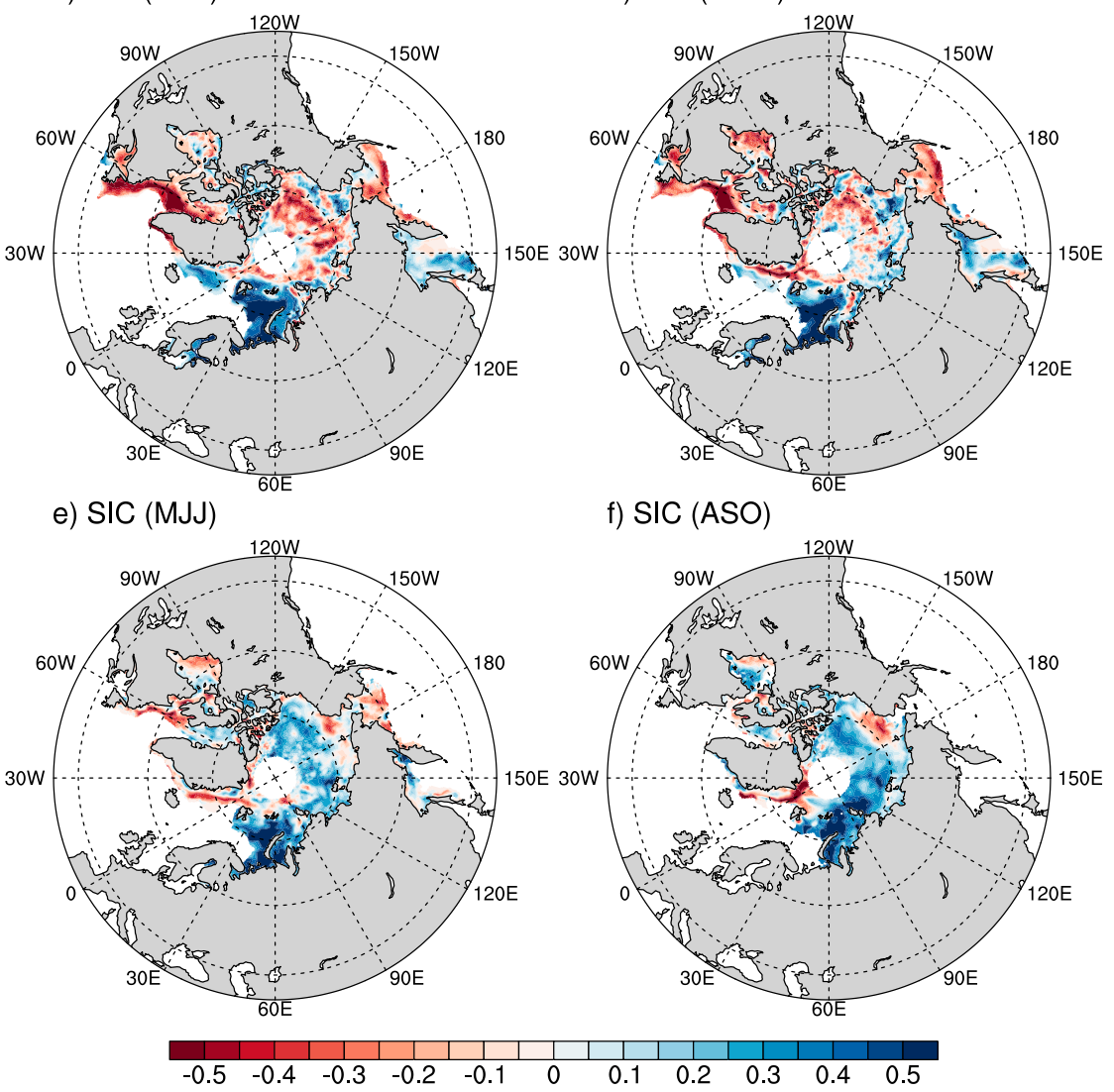

FIG. 9. Correlation coefficients between the NA_dipole index and snow depth anomalies are shown for (a) January-March and (b) March-May. Here, the anomaly is defined as deviation from the monthly climatology. The area where the monthly climatological snow depth is less than $1 \mathrm{~mm}$ of water equivalent is masked out. The correlation coefficients with the sea ice concentration anomaly are shown for (c) January-March, (d) March-May, (e) May-July, and (f) August-October.

dipole. They also demonstrated that the snow depth over western Russia also plays an important role with regard to precipitation variability in northeastern China.

To demonstrate the persistence of the influence of the NA_dipole via Eurasian snow depth and Barents Sea ice concentration, the correlation coefficients between the NA_dipole index and the snow and sea ice anomalies are presented in Fig. 9. For sea ice, the analysis is conducted from late winter (JFM) to late summer (ASO) while, due to its strong seasonality, the snow depth analysis is limited to the period from winter (JFM) to spring [March-May (MAM)]. Consistent with previous studies, there are positive correlations between the NA_dipole and the snow depth over western Russia from JFM to MAM (Figs. 9a,b). This means that an enhanced NA_dipole is associated with an increase in the western Russia snow depth near $55^{\circ}-65^{\circ} \mathrm{N}, 30^{\circ}-60^{\circ} \mathrm{E}$. Interestingly, during JFM and MAM, the correlation pattern remains almost the same, indicating that it persists on seasonal time scales. Although the correlations 

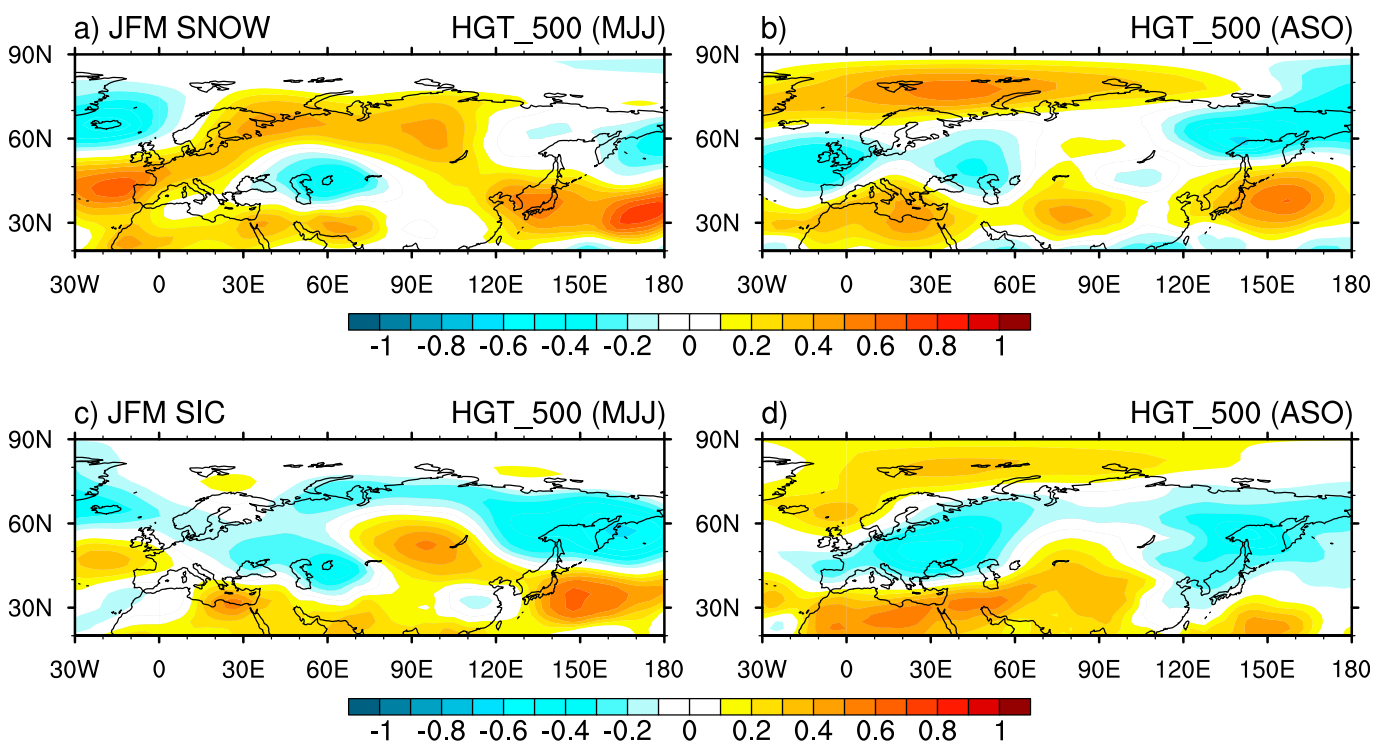

FIG. 10. (a),(b) Correlation coefficients between seasonal-mean 500-hPa geopotential height anomalies and January-March snow depth $\left(55^{\circ}-65^{\circ} \mathrm{N}, 30^{\circ}-60^{\circ} \mathrm{E}\right)$. (c),(d) As in (a) and (b), but between seasonal-mean 500-hPa geopotential height anomalies and January-March sea ice anomalies $\left(70^{\circ}-80^{\circ} \mathrm{N}\right.$ and $\left.40^{\circ}-80^{\circ} \mathrm{E}\right)$. As in Fig. 9 , the anomaly is defined as deviation from the monthly climatology. The seasons for 500-hPa geopotential height anomalies are May-July in (a) and (c) and August-October in (b) and (d).

are not statistically significant, snow depth variability is one of the contributing factors to upper-level wavelike patterns in Eurasia (B. Wu et al. 2009). In addition, from JFM to ASO, it is evident that Barents Sea ice concentration anomalies are positively correlated with the NA_dipole (Figs. 9c-f), and the values exceed the $95 \%$ confidence level $(r>0.44)$. As for the snow depth, the correlation pattern persists for longer than a season. For example, the positive correlations near $70^{\circ}-80^{\circ} \mathrm{N}$ and $40^{\circ}-80^{\circ} \mathrm{E}$ are observed in all four seasons. We also used SPI6 Oct to examine the correlations with snow depth and with sea ice, respectively, and found almost identical patterns to Fig. 9 (not shown).

To examine the physical linkage, we take the JFM snow depth anomaly over western Russia (i.e., $55^{\circ}-65^{\circ} \mathrm{N}$, $\left.30^{\circ}-60^{\circ} \mathrm{E}\right)$ and the sea ice concentration anomaly over the Barents Sea (i.e., $70^{\circ}-80^{\circ} \mathrm{N}, 40^{\circ}-80^{\circ} \mathrm{E}$ ), respectively, and carry out a lagged correlation analysis with HGT 500 for MJJ and ASO, respectively (Fig. 10). (The results can be compared to the lagged correlation between the NA_dipole and HGT_500 in Fig. 8.) For the snow depth anomaly over the western Russia, a positive correlation is observed across the Korean Peninsula, Japan, and the subtropical North Pacific for both MJJ and ASO (Figs. 10a,b). This resembles the patterns in Figs. $8 \mathrm{a}$ and $8 \mathrm{~b}$. For the Barents Sea ice concentration, a similar pattern is observed. As seen in Fig. 8, HGT_500 exhibits a positive correlation over Japan and the subtropical North Pacific, especially during MJJ (Fig. 10c) although, during ASO, a positive correlation can be found off the Korean Peninsula, near $30^{\circ} \mathrm{N}$ and $150^{\circ} \mathrm{E}$ (Fig. 10d). These results in Fig. 10 suggest that the southeasterly anomaly associated with anticyclonic circulations can transport anomalous moisture over the Korean Peninsula, which will then contribute to enhanced precipitation.

Not only the circulation patterns described above, but the vertical motion is also affected by the NA dipole, the western Russia snow depth, and the Barents Sea ice. The negative correlations in the Korean Peninsula are manifest between OMG_500 and the NA_dipole (Figs. 8d-f). These correlations indicate that higher (lower) NA_dipole tend to promote ascending (descending) motion in the Korean Peninsula, which eventually increase (decrease) precipitation in South Korea (Figs. 8g-i). The same is true for more (less) snow depth in the western Russia and more (less) sea ice in the Barents Sea (Figs. 11b and 11d, respectively), since analogous correlation patterns are found between OMG_500 and the western Russia snow depth (Fig. 11a) as well as between OMG_500 and the Barents Sea ice (Fig. 11c). The findings in Figs. 8-11 suggest that the NA_dipole affect warm season precipitation in South Korea through modulating Eurasia snow depth and polar sea ice, which change midtropospheric horizontal circulation patterns and vertical motions in East Asia. 
OMG_500

a)

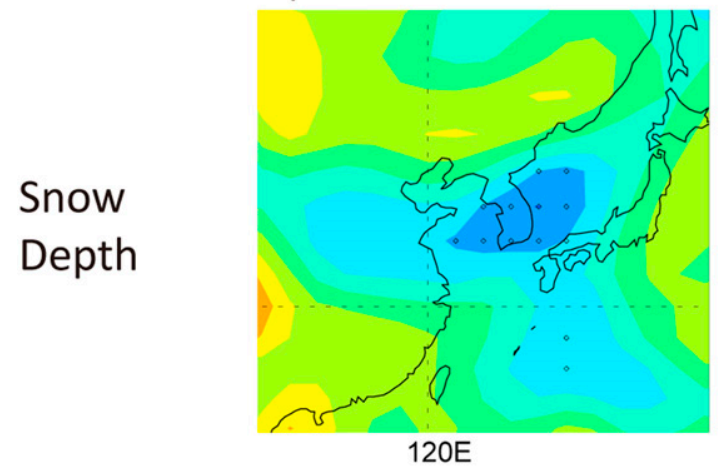

c)

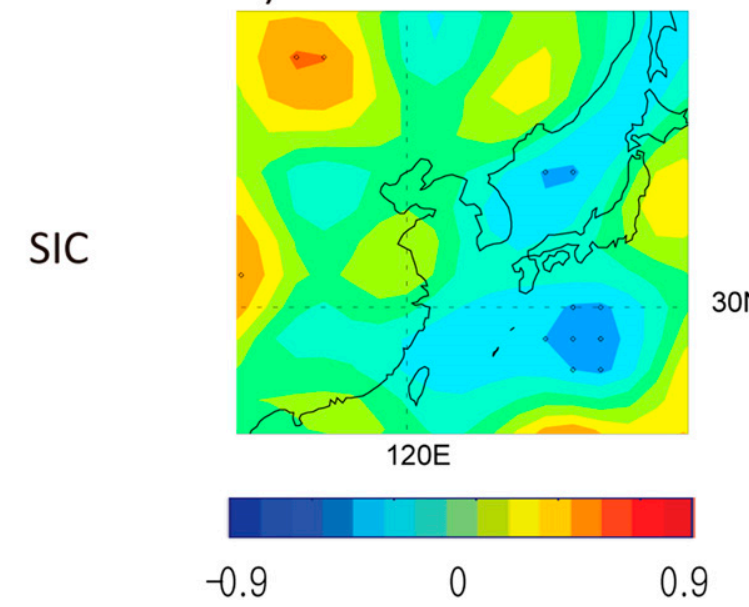

b)

CRU_Precip

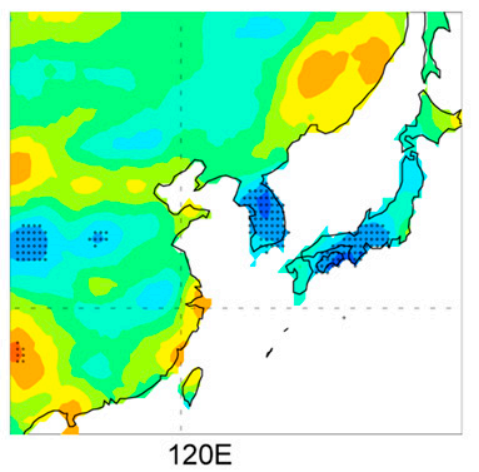

d)

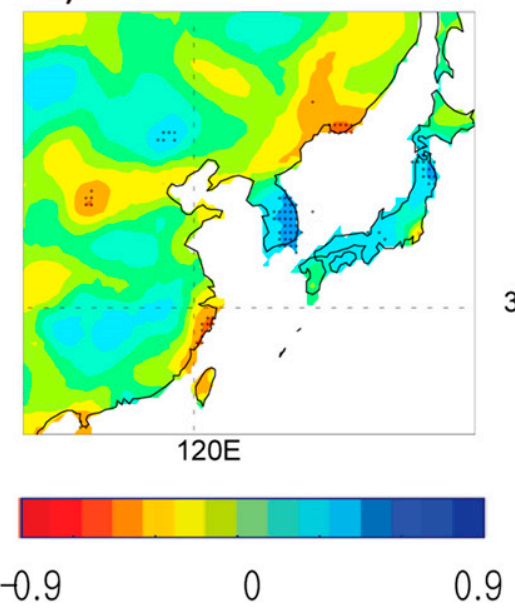

$30 \mathrm{~N}$

$30 N$

FIG. 11. Correlation coefficients between the January-March snow depth index (i.e., $55^{\circ}-65^{\circ} \mathrm{N}, 30^{\circ}-60^{\circ} \mathrm{E}$ ) with the warm season (a) 500-hPa vertical velocity (OMG_500) and with (b) the CRU precipitation. (c),(d) The correlation coefficients between the January-March mean sea ice index (i.e., $70^{\circ}-80^{\circ} \mathrm{N}, 40^{\circ}-80^{\circ} \mathrm{E}$ ) with $\mathrm{OMG} 5500$ and CRU precipitation, respectively. The snow depth index and the sea ice index are the indices used in Fig. 9. The warm season is from May to October. Regions statistically significant at the $95 \%$ confidence level are indicated by dots.

The NI and NP may also affect warm season precipitation in South Korea. In particular, a warmer Indian Ocean [e.g., the Indian Ocean basinwide (IOBW) mode] has been known to increase precipitation in East Asia, including South Korea by inducing anticyclonic circulations in extratropical North Pacific encompassing the area east of Japan (Yang et al. 2007).

\section{c. Development of an empirical predictive model and testing}

To select predictors among the NA_dipole, E_JP, NI, and NP to build a predictive model, we have tested all possible combinations of the four potential predictors (from single to four variables) regressing against SPI6_Oct, which are summarized in Table 3. Note that the cases with $R^{2}>0.5$ only are shown. The result shows that the highest adjusted $R^{2}$ is obtained when the regression model is built with the two variables, the NA_dipole and E_JP. In addition, for all the cases, $p$ values of the NA_dipole and E_JP are less than 0.05 while those of the NP and NI are not. Therefore, choosing the NA_dipole and E_JP as independent variables, we develop an SST-based empirical model for predicting SPI6_Oct, as represented in Eq. (1):

SPI6_Oct $=0.405+1.018 \times$ NA_dipole $+0.652 \times$ E_JP.

The NA_dipole and E_JP in JFM do not have a multicollinearity issue [variance inflation factor (VIF) = 1.0] because they are independent of each other. Although the NA_dipole influences HGT_500 east of 
TABLE 3. Performance $\left(R^{2}\right.$, adjusted $R^{2}$, and $p$ value of variable) of various combinations of the four predictors for SPI6_Oct (1995-2017). Only the cases with $R^{2}$ greater than 0.5 are shown. Bold text indicates statistical significance at the $95 \%$ level.

\begin{tabular}{clccc}
\hline \hline No. of variables & \multicolumn{1}{c}{ Predictors } & $R^{2}$ & Adjusted $R^{2}$ & $p$ value of variable \\
\hline 1 & NA_dipole & 0.54 & 0.52 & 0.00 \\
2 & NA_dipole, E_JP & 0.66 & 0.62 & $0.00,0.01$ \\
& NA_dipole, NP & 0.58 & 0.54 & $\mathbf{0 . 0 0}, 0.16$ \\
& NA_dipole, NI & 0.56 & 0.52 & $\mathbf{0 . 0 0}, 0.31$ \\
3 & NA_dipole, E_JP, NP & 0.66 & 0.61 & $\mathbf{0 . 0 0 , 0 . 0 4 , 0 . 4 5}$ \\
& NA_dipole, E_JP, NI & 0.66 & 0.60 & $\mathbf{0 . 0 0}, \mathbf{0 . 0 3}, 0.84$ \\
4 & NA_dipole, NP, NI & 0.59 & 0.52 & $\mathbf{0 . 0 0 , 0 . 3 0 , 0 . 7 0}$ \\
& NA_dipole, E_JP, NP, NI & 0.67 & 0.59 & $\mathbf{0 . 0 0}, \mathbf{0 . 0 5}, 0.47,0.90$ \\
\hline
\end{tabular}

Japan during the warm season (Fig. 8), SST in the E_JP, which is strongly affected by the subtropical western Pacific (e.g., the Pacific-Japan pattern), can also modulate upper-level circulation patterns in east of Japan during the warm season (Nitta 1987; Kosaka and Nakamura 2006). The training period is the 20 years from 1995 to 2014 , whereas the prediction period is the three years from 2015 to 2017 . While the coefficients of the empirical model vary for different training periods, the coefficients of Eq. (1) are calculated based on the training period.

Figure 12 shows that the SPI indices for these three years, especially for successively dry conditions, are predicted well. Leave-one-out cross-validation for the 1995-2017 period produces a CC of 0.76 between the observed and predicted SPI6_Oct values and a root-mean-square error (RMSE) of 0.64 . The ratio of the RMSE to the standard deviation of the measured data (RSR; Moriasi et al. 2007) is 0.62, which suggests that the prediction power is between "good" and "satisfactory" (Moriasi et al. 2007). This is encouraging, especially when considering the long lead time (6 months). While the NA_dipole and E_JP are significant at the $95 \%$ confidence level as indicated in Table 3, the NA_dipole explains $47 \%$ of the total variability, indicating that winter conditions in the North Atlantic are important to precipitation variability and droughts during the warm season in South Korea.

\section{d. Hybrid machine learning model testing}

With the selected model parameters for the number of trees and the maximum depth of tree growth (Table 4), we compare the performance of the hybrid machine learning model with potential predictors (ML_PP) to the model without potential predictors (ML) to examine the contribution of the potential predictors, the NA_dipole, E_JP, NI, and NP, for the period of 2015-17 (Table 5). Model performance is assessed based on the mean absolute error (MAE) of SPI6, the CCs between the predictions and observations, and RSR for all conditions (total MAE, total CC, and total RSR) and for drought conditions only (SPI6 $<-1.0$; drought MAE, drought CC, and drought RSR) as displayed in Table 5. Welch's $t$ tests for absolute error and Fisher transformation and $z$ tests for the CCs are conducted to determine if any differences in the performance indicators are statistically significant. Cases where the errors for ML_PP are significantly smaller than those for ML and where the CCs for ML_PP are significantly larger than those for ML (one-tailed $p$ value $<0.05$ ) are indicated by bold text in Table 5 .

It is found that the MAE values for ML_PP are smaller than those for ML except for total MAE with a

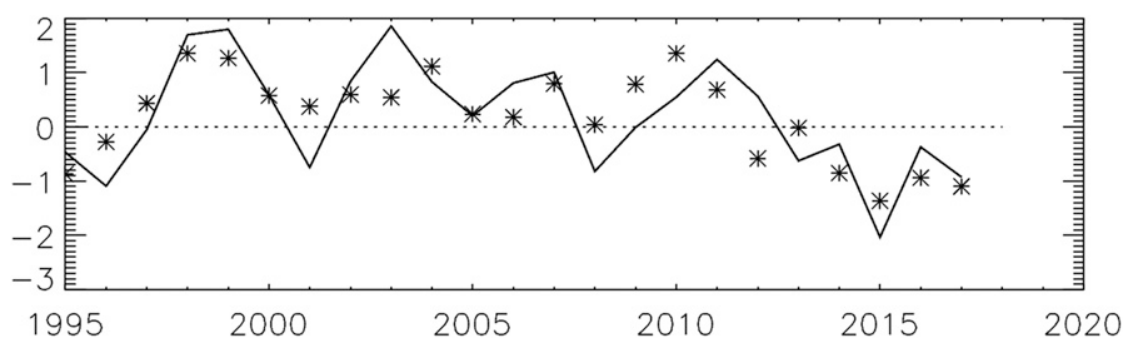

FIG. 12. Observed (black solid line) and predicted (star) SPI6_Oct from 1995 to 2017. All years are cross validated using a leave-one-out test (see the text for details). The correlation coefficient between the observation and the prediction is 0.76 , and the ratio of the root-meansquare error to the standard deviation of measured data (RSR) is 0.62 . 
TABLE 4. Model parameters selected.

\begin{tabular}{|c|c|c|c|c|}
\hline \multirow[b]{2}{*}{ Lead (months) } & \multicolumn{2}{|c|}{ Without potential predictors (ML) } & \multicolumn{2}{|c|}{ With potential predictors (ML_PP) } \\
\hline & No. of trees & Maximum depth of tree growth & No. of trees & Maximum depth of tree growth \\
\hline 1 & 10 & 10 & 10 & 15 \\
\hline 2 & 50 & 10 & 10 & 15 \\
\hline 3 & 50 & Full growth & 10 & 10 \\
\hline 4 & 10 & 5 & 10 & 10 \\
\hline 5 & 10 & 15 & 10 & 15 \\
\hline 6 & 50 & Full growth & 50 & 3 \\
\hline
\end{tabular}

1-month lead time, and most of the differences are statistically significant, although the magnitudes of the errors are quite large with longer lead times. Also, the CCs for ML_PP are mostly larger than those for ML (Table 5). RSR values for ML_PP are smaller than those for ML except for total RSR with a 1-month lead time. Total RSR with a 1-month lead time is very good $(0.0 \leq \mathrm{RSR} \leq 0.5$; Moriasi et al. 2007), Drought RSR with a 1 -month lead time is good $(0.5<\mathrm{RSR} \leq 0.6$; Moriasi et al. 2007), and total RSR with a 2-month lead time is satisfactory $(0.6<\mathrm{RSR} \leq 0.7$; Moriasi et al. 2007).

The contribution of the potential predictors can also be assessed using the feature importance of the machine learning models, which is calculated as the increased sum of squared errors when data for the variable of interest are randomly permutated (Breiman et al. 1984). The sum of the feature importance for input variables is 100. Although SPI6_P and SPI6_F are the most important variables for the 1- and 2-month lead predictions, the importance of the potential predictors, especially the NA_dipole, increases dramatically with longer lead times (Table 6), which is consistent with the high significance of the NA_dipole in the empirical model testing reported in section $3 \mathrm{c}$.

SPI6 prediction maps for 2015 with 2-, 4-, and 6-month lead times are shown in Fig. 13 as an example. The spatial distribution of the drought conditions is depicted accurately in the 2-month-lead prediction maps (Figs. 13b,c). Although the prediction errors are larger with a longer lead time, the models also predict dry conditions with a 4- and 6-month lead time (Figs. 13d-g), and the performance of ML_PP (Figs. 13d,f) is better than that of ML (Figs. 13e,g), especially in the southwestern part of the domain. It should be noted that the most extreme drought conditions (SPI6 $<-2.0$ ) are not predicted accurately with a 2-month lead time despite the relatively low error (total MAE $=0.43$, drought MAE $=0.40$, total RSR $=0.61$ for ML_PP) and high correlations (total CC and drought $\mathrm{CC}=0.8$ for ML_PP). This is mainly because there are limited samples in the training data from 1995-2014 representing these conditions (only nine samples with an SPI6 $<-2.0$, and none with an SPI6 $<-2.3)$, whereas there are many in the test data from 2015-17 (33 samples with an SPI6 $<-2.0$, and 24 among them with SPI $6<-2.3$ ). A longer data period with a full range of drought conditions could improve the performance of the developed models.

\section{Summary and conclusions}

The present study investigates the characteristics of medium-range droughts during the warm season (May-October) in South Korea, which may often develop into a long-term drought. As a comparison, wet years are also examined. Based on correlation analysis

TABLE 5. Performance measures of mean absolute error (MAE), correlation coefficient, and ratio of the root-mean-square error to the standard deviation of measured data (RSR) of hybrid machine learning models for predicting SPI6 with potential predictors (ML_PP) and without potential predictors (ML). Statistically significant differences based on Welch's $t$ test for absolute errors and $z$ test for correlation coefficients are shown in bold.

\begin{tabular}{|c|c|c|c|c|c|c|c|c|c|c|c|c|}
\hline \multirow[b]{3}{*}{ Lead time (month) } & \multicolumn{4}{|c|}{ MAE } & \multicolumn{4}{|c|}{ Correlation coefficient } & \multicolumn{4}{|c|}{ RSR } \\
\hline & \multicolumn{2}{|c|}{ Total } & \multicolumn{2}{|c|}{ Drought } & \multicolumn{2}{|c|}{ Total } & \multicolumn{2}{|c|}{ Drought } & \multicolumn{2}{|c|}{ Total } & \multicolumn{2}{|c|}{ Drought } \\
\hline & $\mathrm{ML}$ & ML_PP & $\mathrm{ML}$ & ML_PP & $\mathrm{ML}$ & ML_PP & $\mathrm{ML}$ & ML_PP & $\mathrm{ML}$ & ML_PP & ML & ML_PP \\
\hline 1 & 0.23 & 0.24 & 0.26 & 0.24 & 0.95 & 0.95 & 0.87 & 0.88 & 0.33 & 0.35 & 0.58 & 0.55 \\
\hline 2 & 0.54 & 0.43 & 0.44 & 0.40 & 0.68 & 0.80 & 0.67 & 0.80 & 0.75 & 0.61 & 0.9 & 0.84 \\
\hline 3 & 0.98 & 0.87 & 1.37 & 1.15 & 0.49 & 0.61 & 0.25 & 0.24 & 1.27 & 1.14 & 2.57 & 2.25 \\
\hline 4 & 1.08 & 0.88 & 1.72 & 1.35 & 0.36 & 0.49 & 0.08 & 0.14 & 1.4 & 1.19 & 3.07 & 2.54 \\
\hline 5 & 1.19 & 1.07 & 1.75 & 1.55 & 0.38 & 0.45 & 0.17 & 0.36 & 1.51 & 1.34 & 3.16 & 2.79 \\
\hline 6 & 1.21 & 1.07 & 1.78 & 1.70 & 0.19 & 0.61 & 0.19 & 0.53 & 1.55 & 1.38 & 3.25 & 3.02 \\
\hline
\end{tabular}


TABLE 6. Relative importance of input variables of the model with potential predictors. Sum of importance of input variables is 100 .

\begin{tabular}{|c|c|c|c|c|c|c|c|c|c|}
\hline \multirow[b]{2}{*}{ Lead time (month) } & \multicolumn{9}{|c|}{ Feature importance $(\%)$} \\
\hline & SPI6_P & SPI6_F & NA_dipole & E_JP & NP & NI & LAT & LON & ELEV \\
\hline 1 & 55.32 & 37.86 & 3.49 & 0.44 & 1.86 & 0.25 & 0.28 & 0.31 & 0.20 \\
\hline 2 & 54.33 & 25.22 & 3.09 & 5.38 & 3.79 & 3.11 & 2.20 & 1.82 & 1.06 \\
\hline 3 & 23.75 & 11.92 & 22.97 & 14.43 & 8.50 & 5.96 & 7.08 & 4.02 & 1.37 \\
\hline 4 & 10.66 & 6.78 & 31.62 & 12.22 & 7.49 & 8.81 & 14.04 & 6.10 & 2.28 \\
\hline 5 & 9.20 & 7.56 & 22.15 & 9.36 & 7.80 & 12.51 & 17.55 & 8.83 & 5.03 \\
\hline 6 & 1.45 & 0.69 & 52.91 & 13.50 & 13.47 & 16.79 & 0.91 & 0.24 & 0.03 \\
\hline
\end{tabular}

using SPI6_Oct, four potential predictors, including the NA_dipole, are identified. An empirical prediction model is developed using the potential predictors, while a hybrid machine learning drought prediction model is also tested.

While the SST anomalies in the tropical Pacific are not opposite between the dry and wet years, linear barotropic variability of the geopotential height fields is observed in upstream Eurasian regions. In the dry years, positive anomalies in western Europe and negative anomalies west of the Ural Mountains are associated with negative anomalies east of Japan that inhibit the flux of warm moist air from the south and thus reduce precipitation, whereas the opposite occurs in the wet

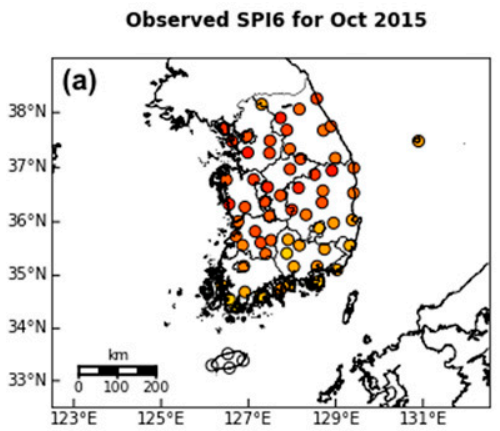

2-m lead SPI6 prediction for Oct 2015

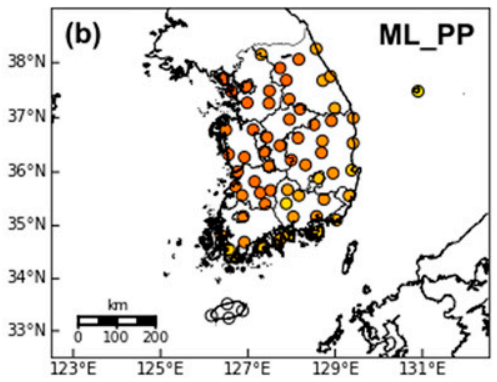

4-m lead SPI6 prediction for Oct 2015

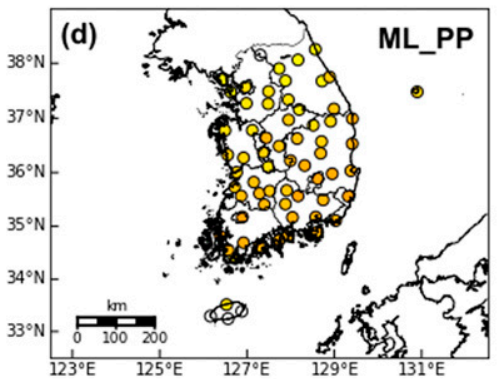

6-m lead SPI6 prediction for Oct 2015

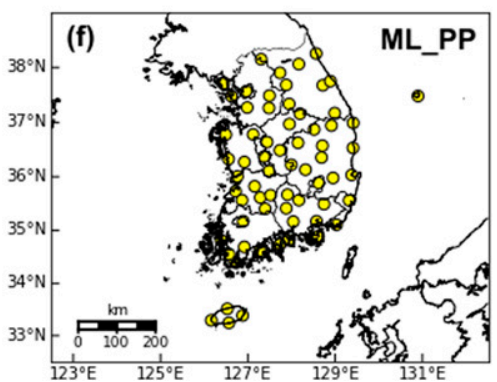

2-m lead SPI6 prediction for Oct 2015

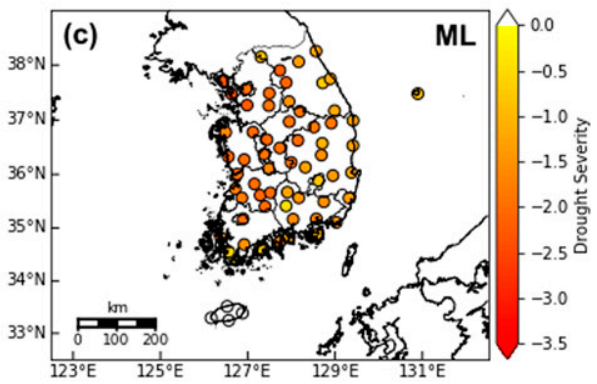

4-m lead SPI6 prediction for Oct 2015

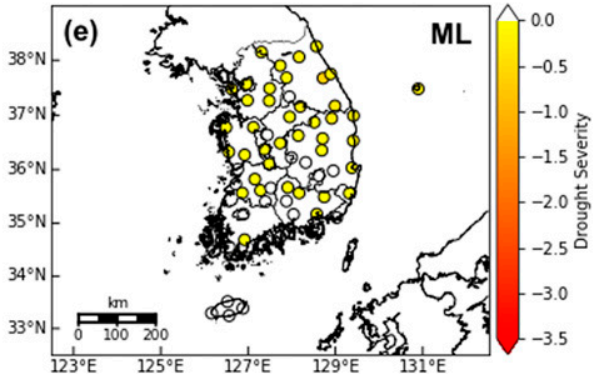

6-m lead SPI6 prediction for Oct 2015

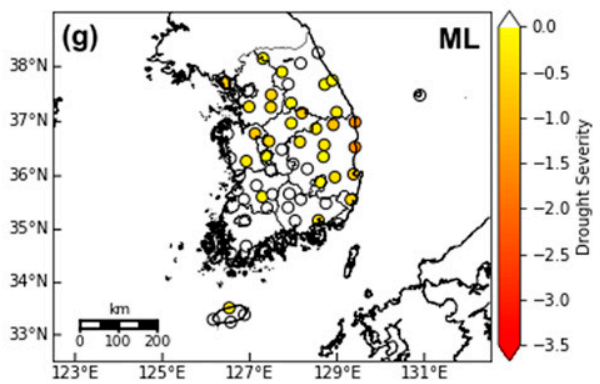

FIG. 13. SPI6 prediction maps for October 2015 with 2-, 4-, and 6-month lead times. 


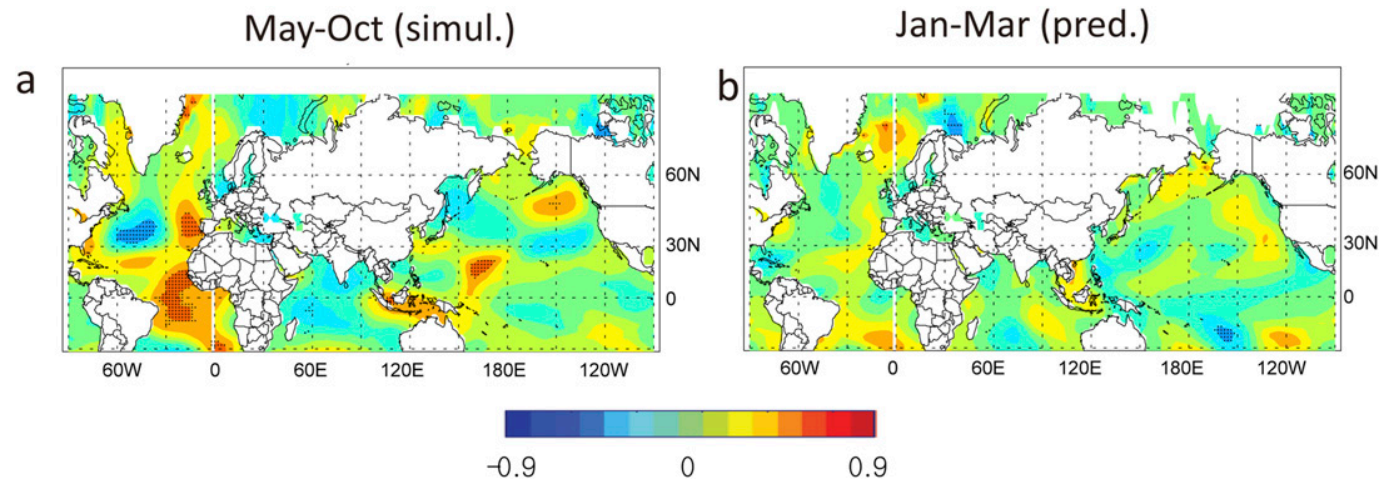

FIG. 14. Correlation map of SPI6_Oct with SST averaged for (a) May-October and (b) January-March for the early 20-yr period (1975-94). Correlations that are statistically significant at the $95 \%$ confidence level are indicated by dots.

years. The equivalent barotropic Rossby wave-like teleconnection from the North Atlantic to East Asia is strongly correlated with the SST difference between the Norwegian Sea and the Barents Sea in JFM (i.e., NA_dipole).

Employing the NA_dipole and E_JP as two predictors, the empirical prediction model is found to well predict the recent drought conditions in 2015 and 2017. Of the two predictors, the NA_dipole plays a more dominant role with longer lead times (e.g., 6 months) by modulating the variability of sea ice in the Barents Sea as well as the snow depth in the Ural Mountain area. In addition, the inclusion of potential predictors is found to substantially improve the predictability of the machinelearning drought prediction models, as illustrated by their smaller errors and higher correlations with the observations. The stronger feature importance of the NA_dipole with longer lead times is also noticeable.

There are some limitations in this study. First, the models are developed based on a period of 20 years, which may not be sufficient to cover the spatial and temporal variability of slowly evolving hydrometeorological parameters. Nevertheless, given that 1) anomalous SST trends have been observed in the central Pacific (e.g., CP-type El Niño) and in the Atlantic (e.g., increased AMO; Yu and Paek 2015; Wang et al. 2017; Vecchi et al. 2017) and that 2) the atmospheric responses to these SST trends have changed accordingly (Kwon et al. 2005; Xiang and Wang 2013; Chen and Zhou 2014; Choi et al. 2017), finding new predictability sources is vital for improving model performance (Trenberth et al. 2015; Wang et al. 2015). The correlation patterns of SPI6_Oct with SST in the past two decades (1995-2014) are very different from those in the two decades previous (1975-94; Fig. 14), indicating that key mechanisms and predictors change between decades. In fact, we tested for the longer period datasets (40 years; 1975-2014) and found that the model performance is low $(\mathrm{CC}=0.3$, RMSE $=0.96$, and RSR $=0.95$ ). Under this circumstance, statistical model development and predictions, based on relatively short but recent periods of time, can be useful information in conjunction with traditional seasonal predictions based on longer periods of time. Recently, it has been noted that winter-to-spring relationships in the atmospheric interannual variability in Eurasia have been enhanced since the early 1990s (Chen et al. 2018). This finding is analogous to the long-lagged impact of NA_dipole on the warm season precipitation variability and droughts in South Korea. Second, the influence of typhoons is not considered in this study. According to data from the National Typhoon Center in South Korea, fewer typhoons affect South Korea in the dry years (2.2) than in the wet years (3.4) during the warm season. Although oceanic and/or atmospheric conditions in dry or wet years may affect the generation and paths of typhoons, more precise investigation is required in the future by separating the impacts of typhoons from total precipitation.

Acknowledgments. This research was supported by the APEC Climate Center. CY is supported by the Korea Polar Research Institute through Grant PN19081.

\section{REFERENCES}

Ahn, J., S. Hong, J. Cho, Y. W. Lee, and H. Lee, 2014: Statistical modeling of sea ice concentration using satellite imagery and climate reanalysis data in the Barents and Kara Seas, 1979-2012. Remote Sens., 6, 5520-5540, https://doi.org/10.3390/rs6065520.

Ahn, J. B., J. H. Ryu, I. H. Cho, J. Y. Park, and S. B. Ryu, 1997: Correlations of temperatures and precipitation in Korea with SSTs in tropical Pacific (in Korean with English abstract). J. Korean Meteor. Soc, 33, 487-495.

Ashok, K., S. Behera, A. S. Rao, H. Weng, and T. Yamagata, 2007: El Niño Modoki and its possible teleconnection. J. Geophys. Res., 112, C11007, https://doi.org/10.1029/2006JC003798. 
Bae, D. H., K. H. Son, and J. M. So, 2017: Utilization of the Bayesian method to improve hydrological drought prediction accuracy. Water Resour. Manage., 31, 3527-3541, https:// doi.org/10.1007/s11269-017-1682-x.

Boo, K. O., W. T. Kwon, and H. J. Baek, 2006: Change of extreme events of temperature and precipitation over Korea using regional projection of future climate change. Geophys. Res. Lett., 33, L01701, https://doi.org/10.1029/2005GL023378.

Breiman, L., J. H. Friedman, R. A. Olshen, and C. J. Stone, 1984: Classification and Regression Trees. Chapman \& Hall/CRC, $358 \mathrm{pp}$.

Capotondi, A., and Coauthors, 2015: Understanding ENSO diversity. Bull. Amer. Meteor. Soc., 96, 921-938, https://doi.org/ 10.1175/BAMS-D-13-00117.1.

Cha, E. J., J. G. Jhun, and H. S. Chung, 1999: A study of characteristics of climate in South Korea for El Niño/La Niña year (in Korean with English abstract). J. Korean Meteor. Soc, $\mathbf{3 5}$, 98-117.

Chen, S., R. Wu, W. Chen, and S. Yao, 2018: Enhanced linkage between Eurasian winter and spring dominant modes of atmospheric interannual variability since the early 1990s. J. Climate, 31, 3575-3595, https://doi.org/10.1175/JCLI-D17-0525.1.

Chen, X., and T. Zhou, 2014: Relative role of tropical SST forcing in the 1990s periodicity change of the Pacific-Japan pattern interannual variability. J. Geophys. Res. Atmos. 119, $13043-$ 13 066, https://doi.org/10.1002/2014JD022064.

Choi, J.-W., Y. Cha, and H.-D. Kim, 2017: Interdecadal variation of precipitation days in August in the Korean Peninsula. Dyn. Atmos. Oceans, 77, 74-88, https://doi.org/10.1016/ j.dynatmoce.2016.10.003.

Comiso, J. C., 2017: Bootstrap Sea Ice Concentrations from Nimbus-7 SMMR and DMSP SSM/I-SSMIS, version 3. NASA National Snow and Ice Data Center Distributed Active Archive Center, https://doi.org/10.5067/7Q8HCCWS4I0R

Dee, D. P., and Coauthors, 2011: The ERA-Interim reanalysis: Configuration and performance of the data assimilation system. Quart. J. Roy. Meteor. Soc, 137, 553-597, https://doi.org/ 10.1002/qj.828

Edwards, D. C., and T. B. McKee, 1997: Characteristics of 20th century drought in the United States at multiple time scales. Climatology Rep. 97-2, Colorado State University Department of Atmospheric Science, 155 pp.

Gastineau, G., and C. Frankignoul, 2015: Influence of the North Atlantic SST variability on the atmospheric circulation during the twentieth century. J. Climate, 28, 1396-1416, https:// doi.org/10.1175/JCLI-D-14-00424.1.

Geurts, P., D. Ernst, and L. Wehenkel, 2006: Extremely randomized trees. Mach. Learn., 63, 3-42, https://doi.org/10.1007/ s10994-006-6226-1.

Guo, D., Y. Gao, I. Bethke, D. Gong, O. M. Johannessen, and H. Wang, 2014: Mechanism on how the spring Arctic sea ice impacts the East Asian summer monsoon. Theor. Appl. Climatol., 115, 107-119, https://doi.org/10.1007/S00704-013-0872-6.

Ho, C. H., W. Choi, J. Kim, M. K. Kim, and H. D. Yoo, 2016: Does El Niño-Southern Oscillation affect the precipitation in Korea on seasonal time scales? Asia-Pac. J. Atmos. Sci., 52, 395-403, https://doi.org/10.1007/s13143-016-0016-x.

Hong, S., B. Park, J. Kim, and H. Jung, 2018: Performance tests and uncertainty analysis of precipitation types. J. Korea Inst. Info. Commun. Eng., 22, 935-942.

Jeong, J. H., H. W. Linderholm, S. H. Woo, C. Folland, B. M. Kim, S. J. Kim, and D. Chen, 2013: Impacts of snow initialization on subseasonal forecasts of surface air temperature for the cold season. J. Climate, 26, 1956-1972, https://doi.org/10.1175/ JCLI-D-12-00159.1.

- , and Coauthors, 2017: The status and prospect of seasonal climate prediction of climate over Korea and East Asia: A review. Asia-Pac. J. Atmos. Sci., 53, 149-173, https://doi.org/ 10.1007/s13143-017-0008-5.

Jung, I.-W., D.-H. Bae, and G. Kim, 2011: Recent trends of mean and extreme precipitation in Korea. Int. J. Climatol., 31, 359370, https://doi.org/10.1002/joc.2068.

Kalnay, E., and Coauthors, 1996: The NCEP/NCAR 40-Year Reanalysis Project. Bull. Amer. Meteor. Soc., 77, 437-472, https://doi.org/10.1175/1520-0477(1996)077<0437:TNYRP> 2.0.CO;2

Kang, I.-S., 1998: Relationship between El Niño and climate variation over Korea peninsula (in Korean with English abstract). J. Korean Meteor. Soc, 34, 390-396.

Kao, H. Y., and J. Yu, 2009: Contrasting eastern Pacific and central Pacific types of ENSO. J. Climate, 22, 615-632, https://doi.org/ 10.1175/2008JCLI2309.1.

Kim, D. W., H. R. Byun, and K. S. Choi, 2009: Evaluation, modification, and application of the effective drought index to 200-year drought climatology of Seoul, Korea. J. Hydrol., 378, 1-12, https://doi.org/10.1016/j.jhydrol.2009.08.021.

Kosaka, Y., and H. Nakamura, 2006: Structure and dynamics of the summertime Pacific-Japan teleconnection pattern. Quart. J. Roy. Meteor. Soc., 132, 2009-2030, https://doi.org/10.1256/ qj.05.204.

Kripalani, R. H., B.-J. Kim, J.-H. Oh, and S.-E. Moon, 2002: Relationship between Soviet snow and Korean rainfall. Int. J. Climatol., 22, 1313-1325, https://doi.org/10.1002/joc.809.

Kug, J. S., F. Jin, and S. I. An, 2009: Two types of El Niño events: Cold tongue El Niño and warm pool El Niño. J. Climate, 22, 1499-1515, https://doi.org/10.1175/2008JCLI2624.1.

, M. S. Ahn, M. K. Sung, S. W. Yeh, H. S. Min, and Y. H. Kim, 2010: Statistical relationship between two types of El Niño events and climate variation over the Korean Peninsula. Asia-Pac. J. Atmos. Sci., 46, 467-474, https://doi.org/10.1007/ s13143-010-0027-y.

Kwon, H.-H., U. Lall, and S.-J. Kim, 2016: The unusual 2013-2015 drought in South Korea in the context of a multicentury precipitation record: Inferences from a nonstationary, multivariate, Bayesian copula model. Geophys. Res. Lett., 43, 85348544, https://doi.org/10.1002/2016GL070270.

Kwon, M., J.-G. Jhun, B. Wang, S.-I. An, and J.-S. Kug, 2005: Decadal change in relationship between East Asian and WNP summer monsoons. Geophys. Res. Lett., 32, L16709, https:// doi.org/10.1029/2005GL023026.

Lau, K.-M., K.-M. Kim, and S. Yang, 2000: Dynamical and boundary forcing characteristics of regional components of the Asian summer monsoon. J. Climate, 13, 2461-2482, https://doi.org/ 10.1175/1520-0442(2000)013<2461:DABFCO > 2.0.CO;2.

Lee, J. H., J. A. Ramirez, T. W. Kim, and P. Y. Julien, 2019: Variability, teleconnection, and predictability of Korean precipitation in relation to large scale climate indices. J. Hydrol., 568, 12-25, https://doi.org/10.1016/j.jhydrol.2018.08.034.

Lee, J. W., and S. Y. Hong, 2014: Potential for added value to downscaled climate extremes over Korea by increased resolution of a regional climate model. Theor. Appl. Climatol., 117, 667-677, https://doi.org/10.1007/s00704-013-1034-6.

Lee, S. E., and K. H. Seo, 2013: The development of a statistical forecast model for changma. Wea. Forecasting, 28, 1304-1321, https://doi.org/10.1175/WAF-D-13-00003.1. 
Lee, W.-S., and M.-I. Lee, 2016: Interannual variability of heat waves in South Korea and their connection with large-scale atmospheric circulation patterns. Int. J. Climatol., 36, 48154830, https://doi.org/10.1002/joc.4671.

Li, H., H. Chen, H. Wang, J. Sun, and J. Ma, 2018: Can Barents Sea ice decline in spring enhance summer hot drought events over northeastern China? J. Climate, 31, 4705-4725, https://doi.org/ 10.1175/JCLI-D-17-0429.1.

Mantua, N. J., S. R. Hare, Y. Zhang, J. M. Wallace, and R. C. Francis, 1997: A Pacific interdecadal climate oscillation with impacts on salmon production. Bull. Amer. Meteor. Soc., 78, 1069-1080, https://doi.org/10.1175/1520-0477(1997)078<1069: APICOW $>2.0 . \mathrm{CO} ; 2$.

Moriasi, D. N., J. G. Arnold, M. W. Van Liew, R. L. Bingner, R. D. Harmel, and T. L. Veith, 2007: Model evaluation guidelines for systematic quantification of accuracy in watershed simulations. Trans. ASAE, 50, 885-900, https://doi.org/10.13031/ 2013.23153.

Nitta, T., 1987: Convective activities in the tropical western Pacific and their impact on the Northern Hemisphere summer circulation. J. Meteor. Soc. Japan, 65, 373-390, https://doi.org/ 10.2151/jmsj1965.65.3_373.

Park, H.-L., K.-H. Seo, and J.-H. Son, 2015: Development of dynamics based statistical prediction model for the changma onset. J. Climate, 28, 6647-6666, https://doi.org/10.1175/JCLID-14-00502.1.

Park, J. C., N. Kim, M. J. Kang, and K. S. Ryoo, 2009: A study on confidence evaluation of the observed data according to the rain gauges installation conditions. J. Environ. Sci. Int., 18, 1115-1121, https://doi.org/10.5322/JES.2009.18.10.1115.

Park, S., E. Seo, D. Kang, J. Im, and M. Lee, 2018: Prediction of drought on pentad scale using remote sensing data and MJO index through random forest over East Asia. Remote Sens., 10, 1811, https://doi.org/10.3390/rs10111811.

Preethi, B., R. Ramya, S. K. Patwardhan, M. Jujumdar, and R. H. Kripalani, 2019: Variability of Indian summer monsoon droughts in CMIP5 climate models. Climate Dyn., 53, 19371962, https://doi.org/10.1007/s00382-019-04752-x.

Quinlan, J. R., 1986: Induction of decision trees. Mach. Learn., 1, 81-106, https://doi.org/10.1007/BF00116251.

Rhee, J., and J. Im, 2017: Meteorological drought forecasting for ungauged areas based on machine learning: Using long-range climate forecast and remote sensing data. Agric. For. Meteor., 237-238, 105-122, https://doi.org/10.1016/j.agrformet.2017.02.011.

— monitoring networks: A case study for Fiji. Water, 10, 788, https://doi.org/10.3390/w10060788.

Ropelewski, C. F., and P. D. Jones, 1987: An extension of the TahitiDarwin Southern Oscillation index. Mon. Wea. Rev., 115, 21612165, https://doi.org/10.1175/1520-0493(1987)115<2161:AEOTTS> 2.0. $\mathrm{CO} ; 2$.

Seo, K.-H., J.-H. Son, S.-E. Lee, T. Tomita, and H.-S. Park, 2012: Mechanisms of an extraordinary East Asian summer monsoon event in July 2011. Geophys. Res. Lett., 39, L05704, https:// doi.org/10.1029/2011GL050378.

Shin, J. Y., M. Ajmal, J. Yoo, and T. W. Kim, 2016: A Bayesian network-based probabilistic framework for drought forecasting and outlook. Adv. Meteor., 2016, 9472605, https://doi.org/ 10.1155/2016/9472605.

Sohn, S. J., and C. Y. Tam, 2016: Long-lead station-scale prediction of hydrological droughts in South Korea based on bivariate pattern-based downscaling. Climate Dyn., 46, 3305-3321, https://doi.org/10.1007/s00382-015-2770-3.
__ _ _ _ and J. B. Ahn, 2013: Development of a multimodelbased seasonal prediction system for extreme droughts and floods: A case study for South Korea. Int. J. Climatol., 33, 793-805, https://doi.org/10.1002/joc.3464.

Son, H. Y., J. Y. Park, J. S. Kug, J. Yoo, and C. H. Kim, 2014: Winter precipitation variability over Korean peninsula associated with ENSO. Climate Dyn., 42, 3171-3186, https:// doi.org/10.1007/s00382-013-2008-1.

,-- _ and _ - 2016: Precipitation variability in September over the Korean Peninsula during ENSO developing phase. Climate Dyn., 46, 3419-3430, https://doi.org/10.1007/s00382-015-2776-x.

Stephan, C. C., N. P. Klingaman, P. L. Vidale, A. G. Turner, M.-E. Demory, and L. Guo, 2018: A comprehensive analysis of coherent rainfall patterns in China and potential drivers. Part I: Interannual variability. Climate Dyn., 50, 4405-4424, https:// doi.org/10.1007/s00382-017-3882-8.

Sung, M.-K., W.-T. Kwon, H.-J. Baek, K.-O. Boo, G.-H. Lim, and J.-S. Kug, 2006: A possible impact of the North Atlantic Oscillation on the East Asian summer monsoon precipitation. Geophys. Res. Lett., 33, L21713, https://doi.org/ 10.1029/2006GL027253.

Tadesse, T., C. Champagne, B. D. Wardlow, T. A. Hadwen, J. F. Brown, G. B. Demisse, Y. A. Bayissa, and A. M. Davidson, 2017: Building the vegetation drought response index for Canada (VegDRI-Canada) to monitor agricultural drought: First results. GIsci. Remote Sens., 54, 230-257, https://doi.org/ 10.1080/15481603.2017.1286728.

Trenberth, K. E., J. T. Fasullo, and T. G. Shepherd, 2015: Attribution of climate extreme events. Nat. Climate Change, $\mathbf{5}$, 725-730, https://doi.org/10.1038/nclimate2657.

Vecchi, G. A., T. L. Delworth, and B. Booth, 2017: Origin of Atlantic decadal swings. Nature, 548, 284-285, https://doi.org/ 10.1038/nature23538.

Wang, B., B. Xiang, J. Li, P. J. Webster, M. N. Rajeevan, J. Liu, and K. J. Ha, 2015: Rethinking Indian monsoon rainfall prediction in the context of recent global warming. Nat. Commun., 6, 7154, https://doi.org/10.1038/ncomms8154.

Wang, L., J.-Y. Yu, and H. Paek, 2017: Enhanced biennial variability in the Pacific due to Atlantic capacitor effect. Nat. Commun., 8, 14887, https://doi.org/10.1038/ncomms14887.

Watanabe, M., and M. Kimoto, 2000a: Atmosphere-ocean thermal coupling in the North Atlantic: A positive feedback. Quart. J. Roy. Meteor. Soc., 126, 3343-3369, https://doi.org/10.1002/ qj. 49712657017.

_- and —-, 2000b: On the persistence of decadal SST anomalies in the North Atlantic. J. Climate, 13, 3017-3028, https://doi.org/10.1175/1520-0442(2000)013<3017:OTPODS > 2.0.CO;2.

Wu, B., R. Zhang, B. Wang, and R. D'Arrigo, 2009: On the association between spring Arctic sea ice concentration and Chinese summer rainfall. Geophys. Res. Lett., 36, L09501, https://doi.org/10.1029/2009GL037299.

Wu, R., and B. P. Kirtman, 2007: Observed relationship of spring and summer East Asian rainfall with winter and spring Eurasian snow. J. Climate, 20, 1285-1304, https://doi.org/ 10.1175/JCLI4068.1.

Wu, Z., B. Wang, J. Li, and F.-F. Jin, 2009: An empirical seasonal prediction model of the East Asian summer monsoon using ENSO and NAO. J. Geophys. Res., 114, D18120, https:// doi.org/10.1029/2009JD011733.

Xiang, B., and B. Wang, 2013: Mechanisms for the advanced Asian summer monsoon onset since the mid-to-late 1990s. J. Climate, 26, 1993-2009, https://doi.org/10.1175/JCLI-D-12-00445.1. 
Yang, J., Q. Liu, S.-P. Xie, Z. Liu, and L. Wu, 2007: Impact of the Indian Ocean SST basin mode on the Asian summer monsoon. Geophys. Res. Lett., 34, L02708, https://doi.org/10.1029/2006GL028571.

Yeh, S. W., J. S. Kug, B. Dewitte, M. H. Kwon, B. P. Kirtman, and F.-F. Jin, 2009: El Niño in a changing climate. Nature, 461, 511-514, https://doi.org/10.1038/nature08316.

- X. Wang, C. Wang, and B. Dewitte, 2015: On the relationship between the North Pacific climate variability and central Pacific El Niño. J. Climate, 28, 663-677, https://doi.org/ 10.1175/JCLI-D-14-00137.1.

- Y. J. Won, J. S. Hong, K. J. Lee, M. Kwon, K. H. Seo, and Y. G. Ham, 2018: The record-breaking heat wave in 2016 over South Korea and its physical mechanism. Mon. Wea. Rev., 146, 1463-1474, https://doi.org/10.1175/MWR-D-17-0205.1.

Yeo, S. R., S. W. Yeh, Y. Kim, and S. Y. Yim, 2018: Monthly climate variation over Korea in relation to the two types of
ENSO evolution. Int. J. Climatol., 38, 811-824, https:// doi.org/10.1002/joc.5212.

Yim, S.-Y., B. Wang, W. Xing, and M.-M. Lu, 2015: Prediction of Meiyu rainfall in Taiwan by multi-lead physical-empirical models. Climate Dyn., 44, 3033-3042, https://doi.org/10.1007/s00382-014-2340-0.

Yoo, J., H. H. Kwon, T. W. Kim, and J. H. Ahn, 2012: Drought frequency analysis using cluster analysis and bivariate probability distribution. J. Hydrol., 420-421, 102-111, https:// doi.org/10.1016/j.jhydrol.2011.11.046.

Yu, J.-Y., and H. Paek, 2015: Precursors of ENSO beyond the tropical Pacific. US CLIVAR Variations, No. 13 (1), U.S. CLIVAR Office, Washington, DC, 15-20, https://usclivar.org/sites/ default/files/documents/2015/Variations2015Winter_0.pdf.

Zhang, Y., J. M. Wallace, and D. S. Battisti, 1997: ENSO-like interdecadal variability: 1900-93. J. Climate, 10, 1004-1020, https:// doi.org/10.1175/1520-0442(1997)010<1004:ELIV>2.0.CO;2. 